DAVID M. CUTLER

Harvard University

LAWRENCE F. KATZ

Harvard University

\title{
Macroeconomic Performance and the Disadvantaged
}

A LONG-STANDING, positive relationship between the economic wellbeing of the poor and the growth of the economy has changed. In the 1960s rapid economic growth and a relatively stable macroeconomy were associated with a 10 percentage point reduction in the proportion of people living below the official poverty line. Unstable macroeconomic conditions in the 1970s were associated with no progress against poverty, and the recession of the early 1980s brought substantial increases in poverty. Despite a sustained macroeconomic expansion from 1983 to 1989 , however, poverty reduction was only moderate. The poverty rate in 1989, for example, was more than 1 percentage point higher in 1989 than in 1979. Thus, although the experience of the 1960s had suggested that a "rising tide raises all boats," persistent poverty in the 1980 s indicates a weakening in the trickle-down mechanism.

In this paper, we explore how disadvantaged individuals and families (those in the lower part of the income distribution) fared from the economic growth of the 1980s. We start by documenting the seeming ineffectiveness of macroeconomic growth to help the disadvantaged during this period. Movements in both the poverty rate and family income inequality indicate a break in the relationship between macroeconomic

We are grateful to David Ellwood, Rachel Friedberg, Claudia Goldin, Christopher Jencks, Dale Jorgenson, and Daniel Slesnick for helpful discussions and comments, and to David Lee for outstanding research assistance. This research was supported by the National Science Foundation (Katz) and the Alfred P. Sloan Foundation (Cutler). The data used in this paper are available from the authors on request. 
performance and inequality beginning about 1983 . Forecasts of poverty rates and family income shares based on equations estimated with data through 1983 underpredict poverty in 1989 by 2.1 to 3.4 percentage points and substantially overpredict the share of income accruing to the lowest quintile.

Next we assess some alternative explanations for the changing relationship between macroeconomic activity and the income of the poor. We find that increased family income inequality is largely associated with increased wage inequality, particularly for primary earners. By contrast, shifts in labor's share of national income do not play an important role in increased inequality. Thus, explanations for why the problems of the disadvantaged appear to have worsened in a period of apparent prosperity must focus on the factors that have shifted relative labor demand away from less skilled workers and generated tremendous increases in wage inequality.

To examine the determinants of economic well-being requires a reliable measure of material welfare. Although government statistics on family incomes clearly suggest a deterioration in the standard of living for a large share of American families over the past two decades, some researchers have started to question whether such income statistics accurately capture changes in the level and distribution of economic wellbeing. Christopher Jencks, for example, has found that more "direct" measures of well-being (like life expectancy and housing conditions) indicate that living standards continued to improve rapidly during the 1970s. ${ }^{1}$ And Susan Mayer and Jencks have argued that alternative measures to income indicate little increase in the inequality of economic wellbeing over the past two decades. ${ }^{2}$

To address these concerns, we move beyond comparisons of current money income in our assessment of the changes in the distribution of economic welfare. To do this, we look at the distribution of consumption in the 1960s, 1970s, and 1980s using household survey data from the Consumer Expenditure Survey (CES). Although consumption data have many problems of their own, the permanent-income hypothesis suggests that changes in the distribution of consumption may measure

1. Jencks (1984).

2. Mayer and Jencks (1991). 
changes in the distribution of economic status more accurately than do changes in the distribution of current money income.

From our examination of household consumption data, we find first that the distribution of consumption is substantially more equal than the distribution of income. This finding is consistent with evidence from earlier household budget studies presented by Milton Friedman in his work on the permanent-income hypothesis. ${ }^{3}$ Our data show that the lowest quintile of the consumption distribution receives about 15 percent more resources than does the lowest quintile of the income distribution.

Second, however, we find that recent trends in the distribution of consumption closely mirror those in the distribution of income. Consumption inequality increased along with income inequality in the $1980 \mathrm{~s}$, particularly for the nonelderly. We also find that the relation between income and consumption appears to deteriorate over the past thirty years, though this deterioration is not serious enough to detract greatly from the usefulness of income comparisons for the nonelderly. We conclude that changes in the distribution of income continue to provide fairly accurate guides to changes in the distribution of economic welfare. But, of course, consumption data and alternative measures of material deprivation and living conditions, such as those proposed by Mayer and Jencks as well as by Jencks and Barbara Torrey, can provide a useful supplement to income comparisons by pinpointing the prevalence of specific material hardships. ${ }^{4}$

Finally, we explore which groups were left behind in the expansion of the 1980s and compare the upward mobility of disadvantaged young workers in the 1960s and 1980s. We find that young families headed by less educated workers fared worst during the 1980s and that the difference in the performance of manufacturing employment between the 1960 s and the 1980s plays an important role in explaining the labor market outcomes for less educated young men.

We conclude that while the disadvantaged are greatly affected by the state of the macroeconomy, economic growth is not the only factor affecting the economic outcomes of the disadvantaged. Strong macroeconomic performance generates more employment opportunities and in-

3. Friedman (1957).

4. Mayer and Jencks (1989); Jencks and Torrey (1988). 
creases the rate at which all individuals are promoted into higher-paying occupations. Differences across U.S. regions and metropolitan areas indicate that changes in the earnings and occupational status of young and less educated workers and changes in family income inequality continued to be closely related to local macroeconomic performance during the 1980s. ${ }^{5}$ The experience of the 1990-91 recession reinforces the perception that the poor bear a disproportionate share of the losses from a recession.

Yet, other factors were not constant during the 1980s. Changes in relative labor demand against the less skilled offset the effects of improved aggregate employment opportunities during the expansion of 1983 to 1989. In an environment of persistent and severe shifts in relative labor demand against the less skilled, a buoyant macroeconomy alone may not be sufficient to improve the absolute and relative living conditions of those from disadvantaged backgrounds. Policies designed to improve the skills of the disadvantaged and a more generous safety net may be necessary to gain ground on poverty even with a booming aggregate economy.

\section{Macroeconomic Growth and the Disadvantaged}

In this section, we document trends in macroeconomic activity, official poverty rates, and family income inequality in the postwar United States. We find a strong inverse relationship between indicators of macroeconomic performance and income-based meas'ures of absolute and relative deprivation through much of this period. However, that relationship has deteriorated since the early 1980 s, leaving a far more unequal distribution of income at the end of the 1980s than would be normally expected.

\section{Macroeconomics and Poverty}

Discussion of the disadvantaged in the United States typically focuses on the fraction of the population with current money incomes below an absolute poverty line. Figure 1 shows the share of the population

5. Bartik (1991); Freeman (1991a). 
Figure 1. Poverty Rate and Poverty-Income Ratio, 1959-89

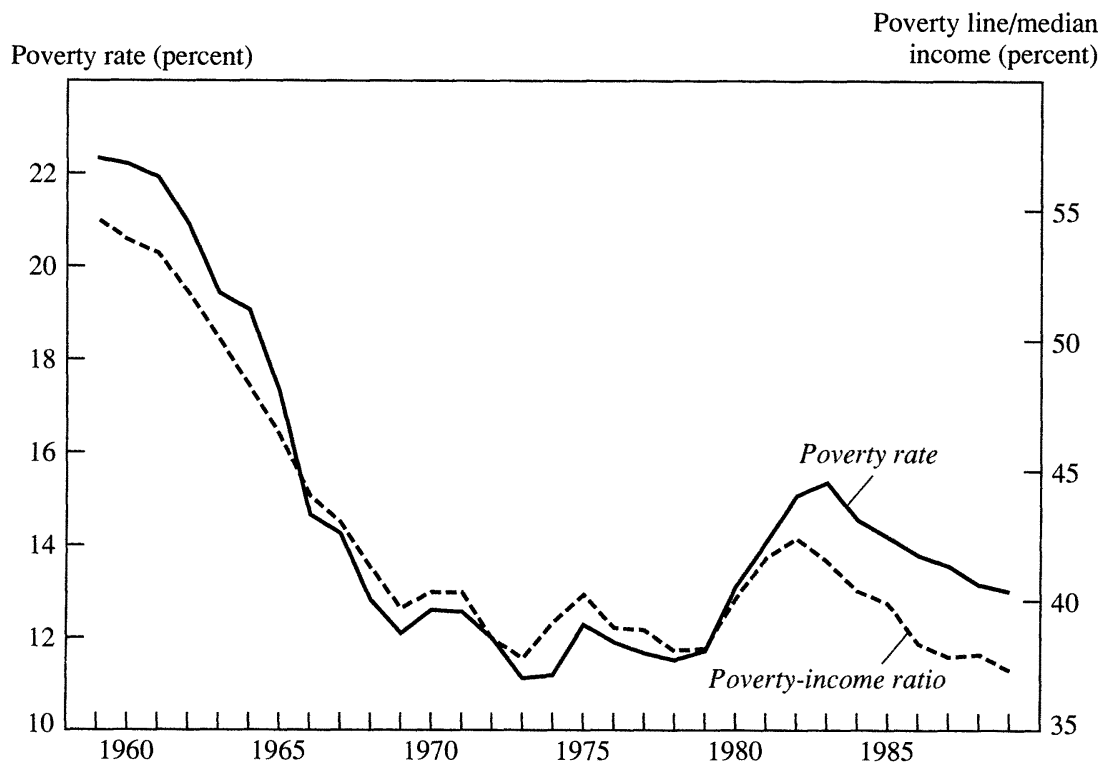

Source: Current Population Surveys. The poverty rate is the official poverty rate, based on annual income data The poverty-income ratio is the average poverty threshold for a family of four divided by median family income.

below the official U.S. poverty line over the past thirty years. This poverty rate is produced by the Census Bureau and is based on annual income data from the March Current Population Surveys, or CPS. The measure has been criticized in various ways. ${ }^{6}$ First, since the family classifications have changed through time, the official poverty rate does not measure a consistent set of people. Second, the official poverty threshold is updated using the consumer price index (CPI), which has historically overweighted house price changes in measuring living costs. Both of these problems tend to overstate poverty in recent years relative to earlier years. For comparison with past research, we use the official measures of poverty in this section; later we show that these two factors do not greatly affect the qualitative nature of our results.

Poverty rates are clearly countercyclical and responsive to the rate of economic growth. Aggregate poverty fell by 50 percent between 1959 and the early 1970s, corresponding to the prolonged expansion of that

6. See Ruggles (1990) for a comprehensive discussion of the problems with the official poverty lines. 
period. In the 1970s, when the economy grew slowly, poverty rates stayed relatively constant. And, in the recession of the early 1980 s, the poverty rate increased almost 4 percentage points. Since 1982, however, the poverty rate has declined only slowly and in 1989 remained above its levels in the late 1970s and far above its nadir of 11.1 percent reached in 1973. As figure 1 indicates, the decline in poverty in the post-1983 macroeconomic expansion was much less rapid than in the long expansion of the 1960s.

Much research has found that trends in poverty are strongly related to the growth of the living standards of the typical family, proxied by median or mean real family income. ${ }^{7}$ The ratio of the average poverty threshold for a family of four to median family income is also displayed in figure 1 . Since the poverty threshold is a fixed real dollar amount, real economic growth that raises incomes throughout the income distribution naturally lowers the share of the population below the threshold. As figure 1 shows, although poverty rates are highly correlated with the ratio of the poverty line to median income, the two series diverge in the 1980s. Median income relative to the poverty line grew rapidly from 1982 to 1989 , but poverty rates fell only slightly. Poverty rates in the late 1980s appear higher than can be explained by the performance of median real family income alone.

Table 1 shows more systematic evidence on the relation between poverty and the macroeconomy. The first row in the table reports regressions of the aggregate poverty rate at time $t\left(p_{t}\right)$ on a variety of contemporaneous macroeconomic indicators: the poverty line-median income ratio $\left([P / Y]_{t}\right)$, the inflation rate $\left(\pi_{t}\right)$, the unemployment rate of prime-aged males $\left(u_{t}\right)$, and a post-1983 time trend $(T)$ :

$$
p_{t}=\beta_{0}+\beta_{1}(P / Y)_{t}+\beta_{2} \pi_{t}+\beta_{3} u_{t}+\beta_{4} T+\epsilon_{t} .
$$

The second row of table 1 shows the results using the ratio of the poverty line to mean income, instead of median income. The two ratios are alternative measures of income distribution relative to the poverty scale. Equations similar to these were the basis for Rebecca Blank and Alan Blinder's estimates of the effects of macroeconomic activity on poverty. ${ }^{8}$

7. See Blank (1991); Blank and Blinder (1986); Blinder and Esaki (1978); Ellwood and Summers (1986).

8. Blank and Blinder (1986). 
Table 1. Regressions Relating Poverty and Macroeconomic Performance, 1959-89

\begin{tabular}{|c|c|c|c|c|c|c|c|}
\hline $\begin{array}{l}\text { Population } \\
\text { group }\end{array}$ & $\begin{array}{l}\text { Poverty } \\
\text { linel } \\
\text { median } \\
\text { income }^{\mathrm{a}}\end{array}$ & $\begin{array}{l}\text { Poverty } \\
\text { line/mean } \\
\text { income }^{\mathrm{a}}\end{array}$ & $\begin{array}{l}\text { Inflation } \\
\text { rate }\end{array}$ & $\begin{array}{c}\text { Un- } \\
\text { employ- } \\
\text { ment } \\
\text { rate }\end{array}$ & $\begin{array}{l}\text { Post- } \\
1983 \\
\text { trend }\end{array}$ & $\begin{array}{c}\text { Lagged } \\
\text { poverty } \\
\text { rate }\end{array}$ & $R^{2}$ \\
\hline Total & $\begin{array}{c}0.645 \\
(0.021)\end{array}$ & $\cdots$ & $\begin{array}{r}-0.078 \\
(0.034)\end{array}$ & $\begin{array}{c}0.277 \\
(0.048)\end{array}$ & $\begin{array}{c}0.346 \\
(0.058)\end{array}$ & $\cdots$ & 0.988 \\
\hline Total & $\cdots$ & $\begin{array}{c}0.669 \\
(0.027)\end{array}$ & $\begin{array}{r}-0.085 \\
(0.041)\end{array}$ & $\begin{array}{c}0.454 \\
(0.057)\end{array}$ & $\begin{array}{c}0.539 \\
(0.076)\end{array}$ & & 0.982 \\
\hline Total & $\begin{array}{c}0.411 \\
(0.066)\end{array}$ & $\ldots$ & $\begin{array}{c}0.028 \\
(0.039)\end{array}$ & $\begin{array}{c}0.263 \\
(0.039)\end{array}$ & $\begin{array}{c}0.232 \\
(0.057)\end{array}$ & $\begin{array}{c}0.388 \\
(0.101)\end{array}$ & 0.991 \\
\hline Total & $\ldots$ & $\begin{array}{c}0.371 \\
(0.067)\end{array}$ & $\begin{array}{c}0.050 \\
(0.040)\end{array}$ & $\begin{array}{c}0.358 \\
(0.046)\end{array}$ & $\begin{array}{c}0.316 \\
(0.073)\end{array}$ & $\begin{array}{c}0.479 \\
(0.098)\end{array}$ & 0.990 \\
\hline Adults (18-64) & $\begin{array}{c}0.405 \\
(0.033)\end{array}$ & $\ldots$ & $\begin{array}{r}-0.038 \\
(0.050)\end{array}$ & $\begin{array}{c}0.509 \\
(0.070)\end{array}$ & $\begin{array}{c}0.353 \\
(0.087)\end{array}$ & $\ldots$ & 0.936 \\
\hline Children $(0-17)$ & $\begin{array}{c}0.690 \\
(0.052)\end{array}$ & $\cdots$ & $\begin{array}{r}-0.008 \\
(0.078)\end{array}$ & $\begin{array}{c}1.050 \\
(0.110)\end{array}$ & $\begin{array}{c}0.881 \\
(0.137)\end{array}$ & & 0.946 \\
\hline Elderly $(65+)$ & $\begin{array}{c}0.473 \\
(0.033)\end{array}$ & $\ldots$ & $\begin{array}{c}-0.239 \\
(0.128)\end{array}$ & $\begin{array}{c}-0.238 \\
(0.197)\end{array}$ & $\begin{array}{c}0.072 \\
(0.247)\end{array}$ & $\ldots$ & 0.970 \\
\hline
\end{tabular}

Sources: Poverty rates are from Bureau of the Census (1991a, tables 1 and 2); poverty line is from Bureau of the Census (1991a, table A1); mean and median income are from Bureau of the Census (1990, tables 10, 11, and 14; and 1991b, tables 13 and 14); inflation rate is from Economic Report of the President, 1990 (table C-58); unemployment rate is from Employment and Earnings, various issues.

The table shows regressions of the form

$$
p_{t}=\beta_{0}+\beta_{1}(P / Y)_{t}+\beta_{2} \pi_{t}+\beta_{3} u_{t}+\beta_{4} T+\epsilon_{t},
$$

where $p_{t}$ is the poverty rate at time $t,(P / Y)_{t}$ is the ratio of the poverty line (the average poverty threshold for a nonfarm family of four) to median or mean family income, $\pi_{t}$ is the inflation rate (measured by changes in the consumer price index), $u_{t}$ is the unemployment rate for men aged $25-54, T$ is a post-1983 time trend, and $\epsilon_{t}$ is the error term. The lagged poverty rate is also included as an independent variable in some equations. Standard errors are in parentheses.

a. Mean or median income is for all families in the first four rows, for families with a household head aged 35-44 in the fifth and sixth rows, and for families with a household head above 65 in the seventh row.

Macroeconomic conditions clearly have important effects on poverty rates. Reductions in the ratio of the poverty line to median income reduce poverty, as do decreases in the unemployment rate. Both are statistically significant in all estimated equations. Also, in both equations an increase in inflation is associated with a reduction in the poverty rate.

Poverty rates in the 1980 s are greater than can be predicted on the basis of macroeconomic conditions alone, however. The post-1983 time trend suggests an unexplained increase in poverty rates of between one-third (using median income) and one-half (using mean income) of a percentage point annually. Since mean income rose more than median income over the period, unexplained poverty is greater using the meanincome ratio. Substantively these estimates are quite large. They imply an unexplained increase in poverty of 2 to 3 percentage points by 1989 . 
One issue in interpreting table 1 is the assumed time structure of the macroeconomic effects-that only contemporaneous inflation and unemployment rates affect poverty rates. Macroeconomic shocks may have a more long-lasting effect on poverty rates, which decline only gradually. To allow for this possibility, we include lagged poverty rates $\left(p_{t-1}\right)$ in our equations as well:

$$
p_{t}=\beta_{0}+\beta_{1}(P / Y)_{t}+\beta_{2} \pi_{t}+\beta_{3} u_{t}+\beta_{4} T+\beta_{5} p_{t-1}+\epsilon_{t} .
$$

The third and fourth rows of table 1 present the results from these equations.

Estimates with the lagged poverty rate yield conclusions similar to the equations without lagged poverty rates. The coefficients on the post1983 trends, for example, suggest that after 1983 annual poverty rates fell by 0.2 to 0.3 percentage point less than would be predicted given historical relationships. The result appears quite robust. Blank presents a variety of alternative specifications and similarly concludes that macroeconomic variables cannot account for the high poverty rates of the late 1980s. ${ }^{9}$

A final issue in these regressions is our assumption of constant coefficients on the macroeconomic variables. The equations in table 1 assume that there is a trend break in poverty only, but no change in the responsiveness to the macroeconomy. To examine this further, we reestimated the equations in rows one and two using data through 1983 and then forecasted poverty through 1989 using those estimates. There is clearly a rapid divergence between actual and predicted poverty rates (see figure 2). Using the median-income equation, the difference is 2.1 percentage points in 1989; using mean income, the difference is 3.4 percentage points. These results are quite close to the predictions from table 1 , suggesting that the assumption of a trend break in poverty rates is justified. Importantly, figure 2 shows no tendency for poverty rates to return to their predicted level over time-the difference between actual and predicted poverty rates was larger in 1989 than in any previous year.

Indeed, in work first reporting on this type of analysis, Blank and Blinder simulate poverty rates in 1989 under alternative post-1983 macroeconomic scenarios. Under a "noncyclical" scenario, in which "unemployment gradually declines to 6.3 percent and inflation remains in

9. Blank (1991). 
Figure 2. Actual and Predicted Poverty Rates, 1959-89

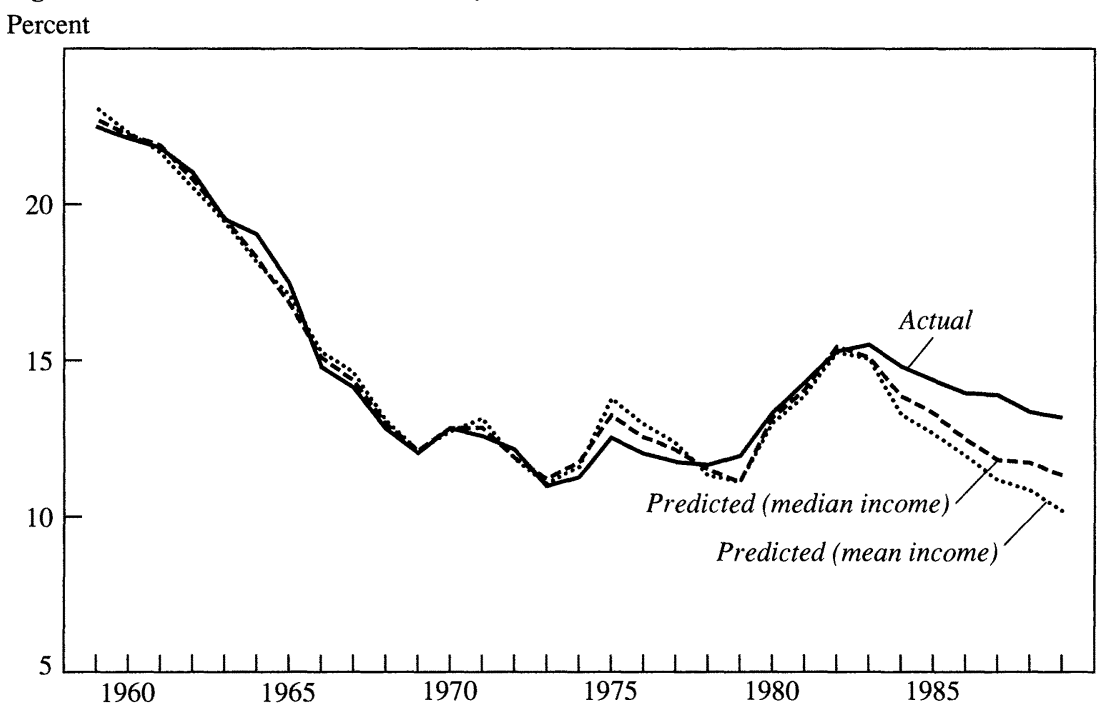

Sources: See table 1. The predicted poverty rates are estimated from the equations in the first two rows of table 1, using data from 1959 to 1983 .

the 4- to 5-percent range," they forecast poverty rates to be 11.1 percent in 1989; the more "pessimistic" scenario, which "has the unemployment rate stall out at 7 percent in 1985 and remain there through 1989," resulted in an 11.5 percent poverty rate. ${ }^{10}$ In reality, macroeconomic performance surpassed even the optimistic "noncyclical" scenario; the actual poverty rate in 1989 , however, was 12.8 percent, a rate exceeding even their gloomiest prediction.

What might have caused the poverty rate to deviate so markedly from its historical course? A variety of factors, ranging from changes in transfer policy to population aging, may affect poverty estimates in ways that our simple time series equations do not capture. Taking a look at transfer policy first, we find that the inclusion of additional aggregate variables designed to capture changes in transfer policy (like the ratio of total transfers to GNP) does not appear to improve the ability to forecast the sluggish decline in poverty rates since 1983 .

Next we examined the potential role of demographic changes. Be-

10. Blank and Blinder (1986, p. 206). 
cause poverty rates for the elderly may be less sensitive to macroeconomic conditions than those for the nonelderly, the increasingly aged population may have caused a strong macroeconomy to generate fewer benefits for the poor. To address this issue, we examined poverty rates separately for the elderly, children, ${ }^{11}$ and working-age adults. Figure 3 shows the trend in poverty rates for these three groups, along with the poverty-income ratio. ${ }^{12}$ The figure reveals a striking difference in poverty rates for the three groups. The dominant source of overall poverty reduction since the mid-1970s has been among the elderly; poverty rates for working-age adults and children appear far less responsive to economic growth. In the early 1960s, poverty rates for the elderly were almost 10 percentage points higher than for any other group; by 1989, poverty among the elderly was almost as low as for working-age adults. The group most adversely affected by trends in the 1980s has been children, whose poverty rate was almost 20 percent in 1989 . The figure suggests a more substantial unexplained poverty trend for children than for either of the other groups.

The remaining part of table 1 confirms that the unexplained increase in poverty is predominantly among persons of working age and children. Here we present regressions similar to those in the first row, using poverty for the three age groups as separate dependent variables. Poverty rates between 1983 and 1989 increased by 0.4 and 0.9 percentage point annually for working-age adults and children relative to predictions from macroeconomic equations. These estimates imply that poverty rates in 1989 were 2 percentage points higher than expected for working-age adults and 5 percentage points higher for children. There was no statistically significant increase for the elderly, however.

The substantial disparity in poverty trends for the three age groups highlights the importance of separating the population by age when examining the effects of macroeconomic performance on poverty. A single explanation for changes in poverty in the post-1983 period will not suffice.

11. Children are defined in official poverty rates as persons below the age of 18 that are related to the head of the family but are not themselves the head of the household or that person's spouse.

12. For the first two groups, we use median income of families headed by a person aged 35-44 in the poverty-income ratio; for the elderly, we use median income of families headed by a person aged 65 or older. Although the age cutoff is for the head of the household rather than the head of the family, most households are composed of only one family. 
Figure 3. Poverty Rate and Poverty-Income Ratio, Selected Age Groups, 1959-88

Poverty line/median

Poverty rate (percent) income (percent)
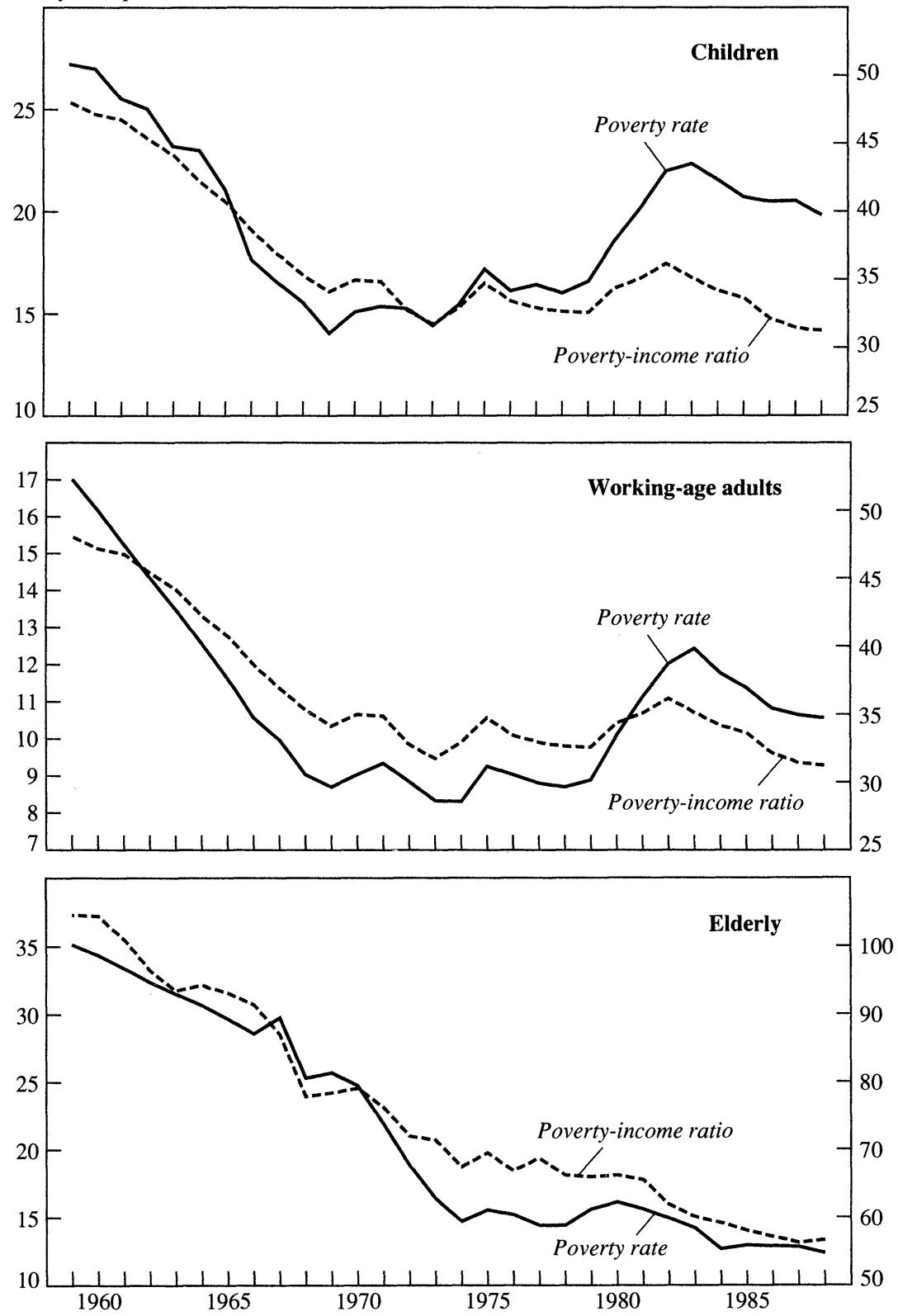

Sources: See figure 1. For working-age adults (aged 18-64) and children (below age 18), the median income for families with a head aged 35-44 is used to calculate the ratio of the poverty level to median income. For the elderly, median income for families with a head above 65 years old is used in the calculations. 


\section{Macroeconomics and Income Distribution}

Although the official poverty rate is a useful indicator of the prevalence of economic hardship in the United States, there are a number of reasons to look at other indicators of the distribution of economic wellbeing. First, since median family income lies above the poverty line and since the income distribution is hump shaped, real income growth will leave a declining share of the population just below the poverty line. The benefits to poverty reduction of a given shift in the income distribution will necessarily decline as well. Second, many object to the use of a fixed absolute poverty line since beliefs about what constitutes a "decent standard of living" are shaped by median or average consumption levels. This suggests the need to examine changes in the shares of income received by different groups to determine whether the impact of macroeconomic performance on the relative incomes of the disadvantaged has changed.

Table 2 shows regressions for the share of income received by quintiles of the income distribution $\left(s_{t}\right)$. We estimate equations similar to those used in table 1 but include the logarithm of real per capita GNP in place of the poverty-income ratio:

$$
s_{t}=\beta_{0}+\beta_{1} \ln G N P_{t}+\beta_{2} \pi_{t}+\beta_{3} u_{t}+\beta_{4} T+\beta_{5} s_{t-1}+\epsilon_{t} .
$$

We present the equations with and without the lagged income-share variables included as explanatory variables.

The evidence in table 2 suggests conclusions very similar to those of the poverty equations in table 1 . The post- 1983 period witnessed a large, unexplained decline in the share of income going to the lowest quintiles and a large increase in the share of income going to the upper end of the distribution. The first three columns of the table show the effects of the macroeconomic variables on income shares. The dominant macroeconomic predictor of changes in the income distribution is the unemployment rate. In periods of low unemployment, the share of income to the lowest three quintiles rises and that to the upper two quintiles declines. Neither inflation nor GNP growth has uniform effects on income shares, and both are sensitive to the form of the estimated equation.

For all income groups, however, the post-1983 period is an outlier in the distribution of income, with a substantial shift in the distribution to- 
Table 2. Regressions Relating Income Distribution and Macroeconomic Performance, 1947-89

\begin{tabular}{lcccccc}
\hline & $\begin{array}{c}\text { Real per } \\
\text { capita }\end{array}$ & $\begin{array}{c}\text { Inflation } \\
\text { rate }\end{array}$ & $\begin{array}{c}\text { Unemploy- } \\
\text { ment rate }\end{array}$ & $\begin{array}{c}\text { Post-1983 } \\
\text { trend }\end{array}$ & $\begin{array}{c}\text { Lagged } \\
\text { income } \\
\text { share }\end{array}$ & $R^{2}$ \\
\hline First (lowest) & 1.03 & 0.0112 & -0.145 & -0.169 & $\ldots$ & 0.754 \\
& $(0.17)$ & $(0.0088)$ & $(0.020)$ & $(0.025)$ & & \\
& 0.52 & 0.0024 & -0.091 & -0.075 & 0.554 & 0.869 \\
& $(0.18)$ & $(0.0085)$ & $(0.018)$ & $(0.026)$ & $(0.099)$ & \\
Second & -0.63 & -0.0241 & -0.161 & -0.205 & $\ldots$ & 0.879 \\
& $(0.19)$ & $(0.0101)$ & $(0.023)$ & $(0.029)$ & & \\
& -0.44 & 0.0030 & -0.088 & -0.057 & 0.634 & 0.957 \\
Third & $(0.15)$ & $(0.0080)$ & $(0.017)$ & $(0.025)$ & $(0.085)$ & \\
& 0.15 & -0.0314 & -0.079 & -0.201 & $\ldots$ & 0.722 \\
& $(0.19)$ & $(0.0102)$ & $(0.023)$ & $(0.029)$ & & \\
& -0.21 & 0.0015 & -0.045 & -0.059 & 0.651 & 0.888 \\
& $(0.15)$ & $(0.0085)$ & $(0.015)$ & $(0.026)$ & $(0.096)$ & \\
Fourth & 1.18 & -0.0194 & 0.068 & -0.111 & $\ldots$ & 0.819 \\
& $(0.12)$ & $(0.0065)$ & $(0.015)$ & $(0.018)$ & & \\
& 0.57 & -0.0047 & 0.042 & -0.069 & 0.420 & 0.828 \\
& $(0.23)$ & $(0.0083)$ & $(0.016)$ & $(0.022)$ & $(0.144)$ & \\
& -1.68 & 0.0640 & 0.318 & 0.674 & $\ldots$ & 0.769 \\
& $(0.50)$ & $(0.0265)$ & $(0.059)$ & $(0.075)$ & & \\
& -0.03 & -0.0075 & 0.185 & 0.219 & 0.648 & 0.907 \\
& $(0.41)$ & $(0.0221)$ & $(0.042)$ & $(0.078)$ & $(0.092)$ & \\
\hline
\end{tabular}

Sources: See table 1. The difference between tables 1 and 2 is that the dependent variable is now the share of income received by different quintiles and the logarithm of real per capita GNP is used in place of the poverty-income ratio. Standard errors are in parentheses.

ward the top quintile and away from the other quintiles. Without the lagged share variables, the trend coefficients suggest a decline of 0.2 percentage point annually in the share of income going to the lowest 60 percent of the distribution and about 0.1 percentage point annually to the fourth quintile. Income in the top quintile increased by 0.67 percentage point annually. With the lagged share, the trend coefficients suggest declines on the order of 0.057 to 0.075 percentage point annually for all but the top quintile of the distribution, which experienced an annual increase of more than 0.2 percentage point. All of these estimates are statistically significant and imply extremely large, unexplained changes in the distribution of income from 1983 to 1989 . Since 1983 the income of the lowest quintile fell between 0.5 and 1.0 percentage point more than macroeconomic variables would predict; income in the top quintile rose between 1 and 4 percentage points more than expected. 
As with the poverty equations, we tested our assumption of common macroeconomic effects using estimates from data through 1983 and predicted income shares in later years. Figure 4 shows the actual and predicted income of the lowest quintile, the highest quintile, and the top 5 percent of the income distribution.

The figure shows striking changes in the income distribution in the 1980s. Before 1960, there was no clear trend in income shares. In the decade of the 1960s, the share of total income received by the lowest quintile increased almost 1 percentage point, with a similar decline in the income share received by the highest quintile (and top 5 percent). Since the mid-1970s, and particularly in the 1980s, however, these gains in income equality have been eliminated. Figure 4 suggests that in 1989 the income share of the lowest quintile was 1 percentage point below its predicted level. The income share of the highest quintile was about 4 percentage points above its predicted level, and the share of the top 5 percent was 3 percentage points above what had been expected. All of these differentials were wider in 1989 than in any previous year, having become progressively larger every year since 1983.

In summary, both the poverty rate and the degree of income inequality increased from the late 1970s to the late 1980s. Although the substantial increases in income inequality and poverty between 1979 and 1983 are not surprising given the deep recession of the early 1980s, the continued widening of the income distribution and the sluggish decline in the poverty rate during the macroeconomic expansion of 1983-89 represent a sharp break from the postwar pattern. We estimate that the overall poverty rate was about 2 percentage points higher in 1989 than it would have been if previous trends had continued. Similarly, the income share of the lowest quintile was 1 percentage point below its predicted value, and the share of the upper quintile was 4 percentage points above its predicted value.

\section{Sources of Increased Poverty and Family Income Inequality}

In this section, we explore potential explanations for the high poverty and increased family income inequality of the 1980s. We first consider whether rising inequality is related to a decline in labor's share of income (both national and personal). Since most families receive little or 
Figure 4. Actual and Predicted Income Shares, Selected Income Groups, 1947-89

Share of total income (percent)
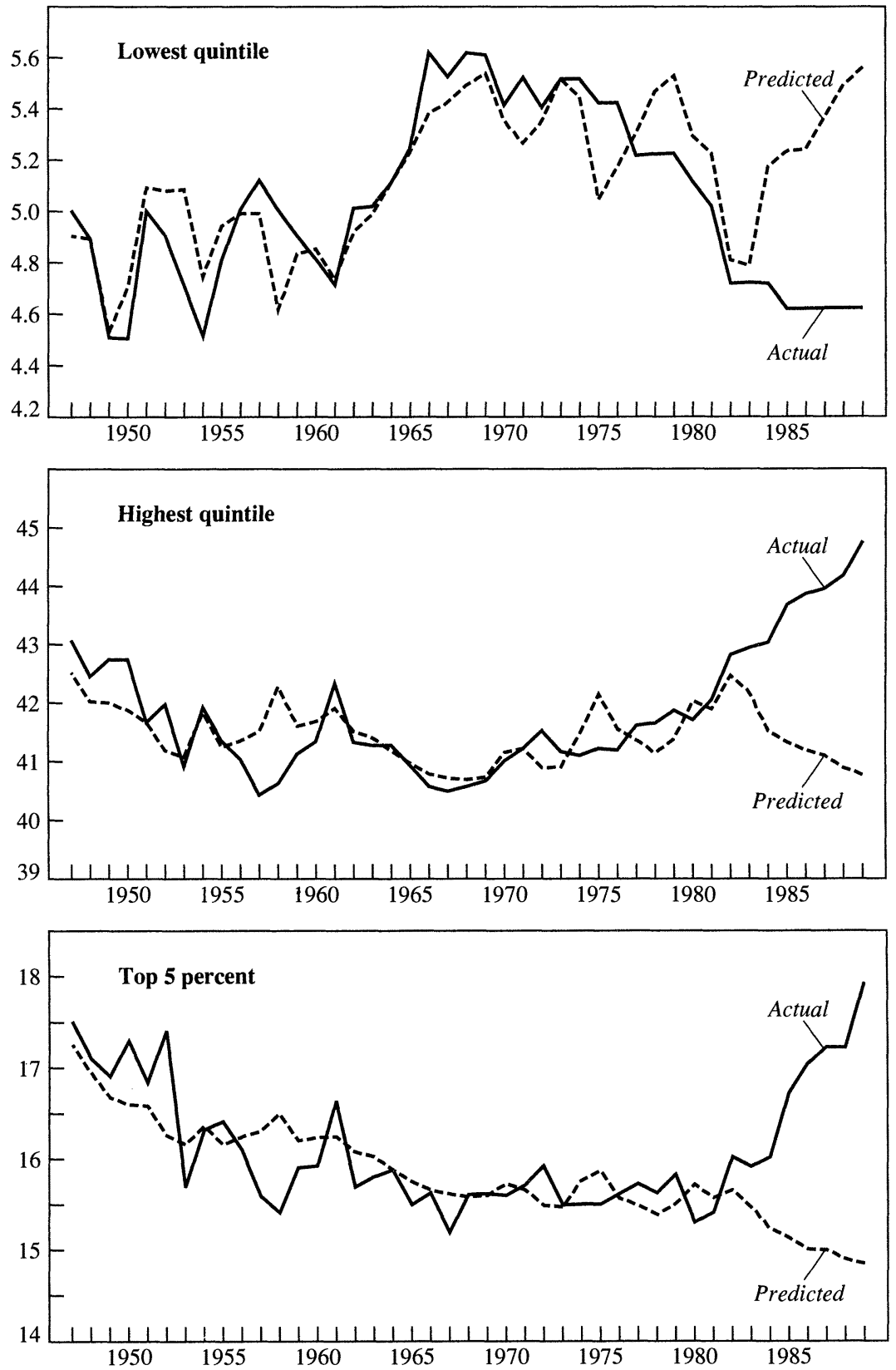

Source: See table 1. The predicted income shares of the lowest and highest income quintiles and of the top 5 percent are estimated using the equations in table 2 with data through 1983. 
no capital income, a shift in national income from labor to capital could generate increased family inequality. We find, however, that labor's share of national output, as conventionally measured, did not decline noticeably during the 1980s. By contrast, labor's share of the types of income that make up family income in household surveys (essentially labor's share of personal income) did decline substantially in the 1980s. The decline in labor's share of personal income reflects, in part, an increase in the share of corporate income distributed as dividends (and thus included in personal income) relative to undistributed corporate profits (which are not included in personal income). Even with this increase in the share of nonlabor income in personal income, the growth of nonlabor income plays only a small role in the overall rise in family income inequality.

We next explore the argument that increased poverty is largely related to changes in family composition. The past three decades have witnessed large changes in family structures-a shift away from marriedcouple families toward single-parent families. Although this change in composition has probably increased the level of poverty and, less clearly, been associated with the increased "feminization" of poverty, we conclude that it is not an important explanation for the failure of poverty to decline in line with historical trends during the 1980s. Even when changes in family structure are controlled for, there was substantially less poverty reduction, and substantially more inequality, in the $1980 \mathrm{~s}$ than in earlier periods displaying similar movements in aggregate economic activity.

Lastly, we examine the components of family income and consider the sources of increased inequality. Although a voluminous literature has examined recent changes in U.S. wage inequality, we consider the relation between changes in the dispersion of head-of-household income and total family income. We ask whether changes in the labor market outcomes of other family members and changes in nonlabor incomes have offset or exacerbated the effects of increased earnings inequality among primary earners. Although the labor market performance of secondary earners has moved in the direction of increasing inequality, we find that most of the change in family income inequality reflects a widening in primary-earner income inequality. We conclude that rising wage inequality associated with a change in the returns to skill is the key to understanding increased family income inequality in the $1980 \mathrm{~s}$. 


\section{Macroeconomic Activity and Payments to Labor}

A first potential explanation for increased inequality and income hardship is that the expansion of the 1980s has disproportionately benefited capital relative to labor. This view is lent some credence by the observation that productivity in nonfarm businesses grew almost 1.5 percent annually since 1982, while the real wages of production and nonsupervisory workers in nonagricultural industries fell. In fact, Lawrence Mishel and David Frankel conclude that "a major reason for the unequal growth in family incomes is that, in recent years, a greater share of our national income has been in the form of capital incomes (such as rent, dividends, interest payments, capital gains) and a smaller share has been earned as wages and salaries." 13

To evaluate this issue, we form two measures of labor's share of output. The first, which we term the factor payments share, is the ratio of labor payments (employee compensation plus two-thirds of proprietors' income) $)^{14}$ to total factor compensation (employee compensation, proprietors' income, net interest, corporate profits, depreciation, and personal rental income). We view this measure as the extent to which labor in aggregate is receiving the fruits of macroeconomic activity. Total employee compensation is not what standard micro data sets measure. The earnings data in the household surveys that are used to study family income inequality only provide information on wages and salaries. Total employee compensation from the national income accounts (NIA) also includes other labor income (employer social-insurance contributions and employer-paid fringe benefits). Further, transfer income, personal interest income, and personal dividend income are all counted in family income measures, but undistributed corporate profits and depreciation are not. Accordingly, we form a second measure of labor's share of pretransfer income, termed the market-based income share, defined as wage and salary payments plus two-thirds of proprietors' income, divided by market-based family incomes (wages and salaries, proprietors' income, personal interest income, personal dividend income, and rental

13. Mishel and Frankel (1991, p. 29).

14. We follow the standard practice of allocating two-thirds of proprietors' income to labor and one-third to capital. Plausible alternative treatments, including omitting proprietors' income entirely, have little effect on these calculations. 
Figure 5. Labor's Share of Output, 1950-89

Share of total factor

Share of market-based payments (percent) family income (percent)

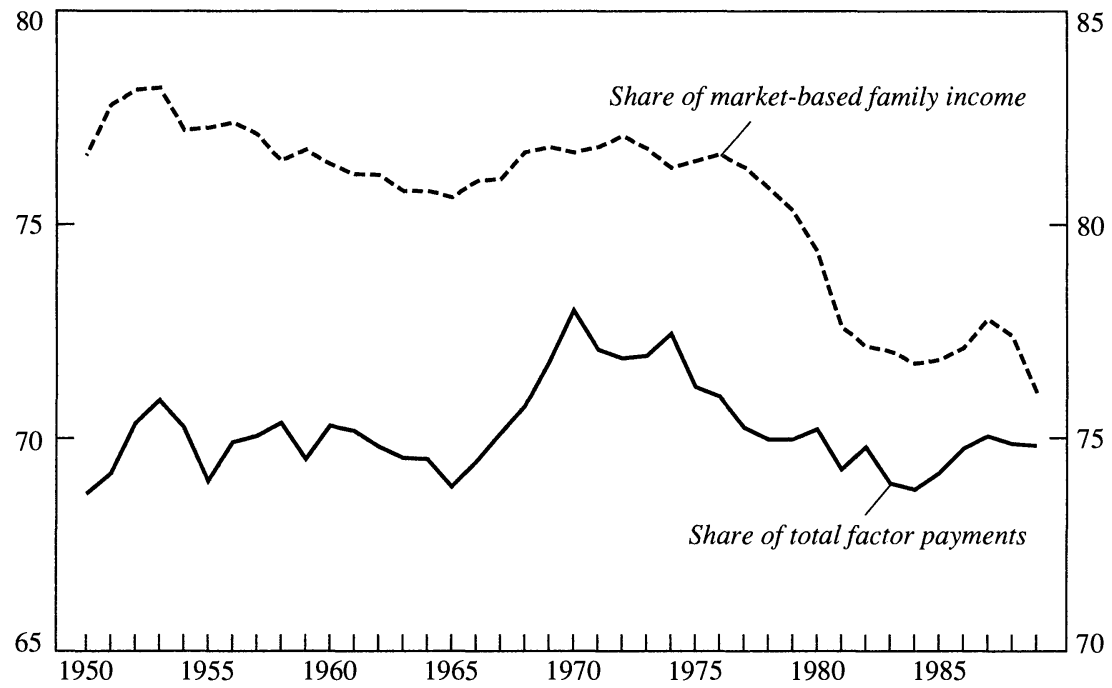

Source: National Income and Product Accounts. Labor's share of total factor payments is total employee compensation plus two-thirds of proprietors' income, divided by the sum of employee compensation, proprietors' income, net interest, rental income, and depreciation. Labor's share of market-based family income is wage and salary payments plus two-thirds of proprietors' income, divided by the sum of wage and salary payments, proprietors' income, personal rental income, and personal dividend and interest income.

income). Market-based income includes the sources of income that are picked up in household survey measures of pretransfer family incomes.

These two measures of labor's share are depicted in figure 5. Labor's share of total factor income was virtually unchanged in the 1980s; it was 70.0 percent in 1979 and 69.7 percent in 1989. Indeed, since 1950, labor's share of output has been relatively stable, with the exception of a brief increase in the late 1960s and early 1970s. But while labor's share of total factor income remained constant, labor's share of market-based income declined, from 80.3 percent in 1979 to 76.0 percent in 1989 . The decline was driven by the growth in capital incomes (particularly personal interest and dividend income) relative to the growth in wages and salaries. From 1979 to 1989 , the sum of real personal interest and dividend income grew by 5.6 percent annually, while personal labor income increased by only 2.4 percent annually. The growth in personal dividend income relative to labor income reflects a shift within the corporate sector from retaining undistributed profits (unrealized capital income) to 
paying out dividends. Since undistributed corporate profits do not show up in measured family income, whereas personal dividend interest does, this shift will increase the contribution of capital income to total family income. The change is most naturally viewed as an accounting shift, however, and not as an increase in the share of output going to capital.

An additional component of the increase in capital income is the rapid growth of personal interest income, particularly government interest payments, in the 1980s. The interpretation of this shift, however, depends on one's view of the incidence of the taxes required to pay for government debt service. We thus conclude that although labor's share of national income has not declined, labor's share of our market-based family income has. If this change were the major factor in rising family inequality, one might interpret part of rising inequality as somewhat illusory, mostly the result of the failure of family income measures to pierce the corporate veil. Unfortunately, as we later document, rising family income inequality is not an illusion. Furthermore, the increase in overall income inequality is dominated by increased inequality of labor income rather than nonlabor income. ${ }^{15}$

\section{Changes in Family Composition}

A second potential explanation for the increase in poverty and family income inequality is a change in the nature of families. The past three decades have witnessed a decline in the share of the population in traditional two-parent families and an increase in the share of the population in single-parent, often female-headed, families ${ }^{16}$ Because poverty rates tend to be higher for single-parent families, shifts in the distribution of the population toward these household types are likely to be associated with increases in measured poverty.

Table 3 shows the distribution of the survey population across family

15. The overall importance of changes in labor income inequality does not mean that other factors do not matter for some groups. In the 1990 Green Book, the Congressional Budget Office (Committee on Ways and Means, 1990) has carefully documented that decreased transfer payments in the bottom quintile do play an important role in the persistence of high poverty rates in the 1980s and that increased capital income in the very top part of the distribution does contribute to the sharp rise in the income share of the top 5 percent of the population.

16. See Bane (1986) and Ellwood (1988) for discussions of the causes and consequences of changes in family structure in the postwar United States. 
Table 3. Family Composition, Selected Years, 1963-89

Percent

\begin{tabular}{lllllll}
\hline & \multicolumn{6}{c}{ Share of persons, by year } \\
\cline { 2 - 7 }$\quad$ Family type & 1963 & 1969 & 1973 & 1979 & 1983 & 1989 \\
\hline $\begin{array}{l}\text { Husband-wife families } \\
\quad \text { With children }\end{array}$ & 64.7 & 61.4 & 56.2 & 49.7 & 46.2 & 43.5 \\
$\quad$ Without children & 20.1 & 21.3 & 23.2 & 24.5 & 25.8 & 25.8 \\
$\begin{array}{l}\text { Male-headed families } \\
\text { Single }\end{array}$ & 2.3 & 2.7 & 3.6 & 5.3 & 5.7 & 6.6 \\
$\quad$ With children & 0.8 & 0.7 & 0.8 & 1.0 & 1.3 & 1.6 \\
Other relatives & 1.0 & 0.9 & 1.0 & 1.1 & 1.1 & 1.5 \\
Female-headed families & & & & & & \\
$\quad$ Single & 3.7 & 4.5 & 5.2 & 6.5 & 7.0 & 7.7 \\
$\quad$ With children & 4.9 & 5.9 & 7.6 & 9.2 & 9.4 & 9.9 \\
$\quad$ Other relatives & 2.5 & 2.6 & 2.5 & 2.9 & 3.5 & 3.4 \\
\hline
\end{tabular}

Source: Authors' calculations based on data from the March Current Population Surveys (CPS). The table shows the share of persons in each family type in the indicated years. Children are persons below the age of 18 related to (but not including) the head of or spouse of the head of the family.

types for six years: $1963,1969,1973,1979,1983$, and 1989. Two of the periods (1963-69 and 1983-89) contain the sustained economic expansions we would like to compare. The other years cover periods with more mixed economic outcomes. The table shows a pronounced decline in the share of persons in husband-wife families with children, from almost 65 percent in 1963 to less than 45 percent in 1989. Some of the decline reflects the aging of the baby-boom generation. In 1963, the first cohort of the baby boom was only 17 years old; in 1989, the last cohort of the baby boom was 25 years old. The increase in husband-wife families without children may be one manifestation of this change. Part of the change in family structure, however, represents a trend toward single family heads away from married-couple families. In 1963, for example, only 5.7 percent of people were in families headed by a single parent with children; by 1989 , the percentage had doubled. ${ }^{17}$

Clearly, these trends in household composition have shifted the population toward household types that are more likely to be poor. For our purposes, however, a more relevant question is whether changes in family composition can explain lackluster poverty reduction in the 1980s relative to the 1960s. Table 3 suggests that these household-composition

17. Ellwood and Crane (1990) document that these changes in family structure have been much more substantial for blacks than for whites. 
trends are unlikely to be a primary factor in explaining patterns in the 1980s. Most of the change in family structure occurred between 1969 and 1979 , with reinforcing, but more moderate, changes in the 1960s and 1980s.

To evaluate more formally the potential effects of household-composition changes on the aggregate poverty rate, we compare changes in actual poverty rates with changes in fixed-weighted poverty rates, constructed by taking the poverty rate for each family type in each year and weighting it by the average share of the population in that family type over the entire period. To the extent that family-structure changes respond to changes in income, adjusting poverty rates for these compositional effects may overstate their importance. We thus treat the unadjusted and adjusted measures of poverty as bounds on the importance of compositional change in affecting trends in the aggregate poverty rate.

Because the poverty rates published by the U.S. government are not revised to reflect periodic changes in the official poverty definition and because the official poverty lines have been adjusted for inflation by a potentially misleading price index, we construct our own set of poverty rates using a consistent methodology over time. Our approach involves making two changes to the published rates. First, official poverty lines have changed through time in a way that increases poverty rates. ${ }^{18}$ For example, poverty thresholds before 1981 were lower for farm than for nonfarm families and for female-headed families than for all other families. To adjust for this, we recompute poverty rates for our sample years with the family equivalence scale used after $1981 .{ }^{19}$ We scale the measure of needs by that for a single person below the age of 65 who lives alone. The equivalence scale then varies along three dimensions: the total number of persons in the family; the age of the household head (above or below age 65); and the presence of related children below age 18. Elderly household heads have a needs measure about 8 percent below that of nonelderly household heads. The poverty scale reflects a high degree of family economies of scale. Relative to the single, nonelderly index of 1.0, a two-adult, nonelderly family has a needs measure of 1.29 , and a two-adult, one-child family has a needs measure of 1.55 .

18. See Bureau of the Census (1991a, pp. 354-56) for a description of major changes in the official poverty definition.

19. Bureau of the Census (1991a, table A-2). 
Second, we update our poverty threshold using the personal consumption expenditures (PCE) implicit price deflator in place of the CPI. The CPI includes the purchase price of new houses as one of its components, and, since the relative price of houses increased substantially in the 1970s and consumers do not purchase new houses regularly, the CPI consumption basket increased faster than the price of a typical commodity bundle. Our alternative index removes this price disparity. ${ }^{20}$

Table 4 shows the resulting poverty rates for all persons and for persons in families not headed by an elderly individual. The table also presents the poverty rates for different types of households. Poverty rates for husband-wife families are generally much lower than those for single-parent families, particularly female-headed families. Almost half of the persons in female-headed families with children have incomes below the poverty line.

The table also shows the unadjusted and adjusted poverty rates. Demographic change has clearly had an important effect on poverty rates over time. Poverty rates in 1963 would have been about 2 percentage points greater had the demographic makeup in that year matched the average over the period. Similarly, poverty rates in 1989 would have been more than 1 percentage point lower without the intervening demographic change. The estimates for both the full sample and the nonelderly sample suggest that gains in the war on poverty have been understated by about 2 to 3 percentage points since 1963, roughly one-quarter to one-half of the measured poverty decline.

The failure of poverty rates to decline further in the 1980s, however, was not a consequence of demographic change, nor was the rapid decline in poverty rates in the 1960 s a result of demographics. Movements in the aggregate unadjusted and adjusted poverty rates were similar in the 1963-69 period ( 7.3 versus 8.0 percent) and the $1983-89$ period ( 2.6 versus 2.2 percent). The same is true for the nonelderly poverty rate. The greatest difference between the unadjusted and adjusted poverty trends is in the $1970 \mathrm{~s}$. The unadjusted poverty measures show a 1.6 percentage point decline in the total poverty rate from 1969 to 1979 , and a 0.4 percentage point decline in poverty among the nonelderly. The adjusted figures suggest declines of 3.7 and 2.3 percentage points respectively. Thus, to the extent that changes in family structure are exogenous, part of the steadiness of poverty rates in the 1970s can be

20. We assume the 1967 poverty line accurately measures the poverty threshold and adjust the threshold from that year. 
Table 4. Poverty and Family Composition, Selected Years, 1963-89

Poverty rate (percent)

\begin{tabular}{lrrrrrr}
\hline \multicolumn{1}{c}{ Family type } & 1963 & 1969 & 1973 & 1979 & 1983 & 1989 \\
\hline $\begin{array}{l}\text { All persons by family type } \\
\text { Husband-wife families }\end{array}$ & & & & & & \\
$\quad$ With children & 17.2 & 8.6 & 7.1 & 7.0 & 10.4 & 7.6 \\
$\quad$ Without children & 12.3 & 7.0 & 4.6 & 3.9 & 4.1 & 3.1 \\
Male-headed families & & & & & & \\
$\quad$ Single & 34.3 & 24.8 & 18.9 & 15.4 & 18.0 & 14.6 \\
$\quad$ With children & 30.6 & 22.4 & 14.8 & 13.0 & 19.8 & 17.0 \\
$\quad$ Other relatives & 13.1 & 10.0 & 7.0 & 5.2 & 6.6 & 6.3 \\
Female-headed families & & & & & & \\
$\quad$ Single & 51.3 & 38.8 & 29.7 & 24.8 & 23.1 & 20.3 \\
$\quad$ With children & 58.2 & 48.3 & 46.3 & 41.3 & 48.3 & 43.8 \\
$\quad$ Other relatives & 18.7 & 14.6 & 9.1 & 9.1 & 11.9 & 8.0 \\
$\begin{array}{l}\text { Overall } \\
\quad \text { Unadjusted }\end{array}$ & & & & & & \\
$\quad$ Adjusted & 20.0 & 12.7 & 11.2 & 11.1 & 13.8 & 11.6 \\
& 22.1 & 14.1 & 11.5 & 10.4 & 13.1 & 10.5
\end{tabular}

Nonelderly persons by family type

Husband-wife families

$\begin{array}{lrrrrrr}\text { With children } & 16.7 & 8.3 & 6.7 & 6.8 & 10.3 & 7.6 \\ \text { Without children } & 8.4 & 3.8 & 3.4 & 2.7 & 3.8 & 2.7\end{array}$

Male-headed families

$\begin{array}{lrrrrrr}\text { Single } & 30.0 & 19.6 & 17.0 & 14.2 & 17.8 & 14.6 \\ \text { With children } & 28.5 & 19.3 & 12.3 & 11.9 & 19.0 & 17.4 \\ \text { Other relatives } & 11.3 & 8.3 & 6.9 & 4.8 & 6.1 & 6.6\end{array}$

Female-headed families

\begin{tabular}{lrrrrrr} 
Single & 39.1 & 29.0 & 26.9 & 22.6 & 23.1 & 20.6 \\
With children & 58.4 & 48.5 & 46.9 & 41.7 & 48.7 & 44.6 \\
$\quad$ Other relatives & 13.0 & 11.6 & 7.7 & 9.0 & 12.7 & 8.8 \\
Overall & & & & & & \\
$\quad$ Unadjusted & 18.3 & 11.0 & 10.4 & 10.6 & 14.1 & 12.0 \\
$\quad$ Adjusted & 20.0 & 12.3 & 10.8 & 10.0 & 13.2 & 10.7 \\
\hline
\end{tabular}

Source: Authors' calculations based on data from the March CPS. Poverty rates for all years are computed using the official family equivalence scale after 1981 and are updated using the personal consumption expenditure deflator in place of the consumer price index. The unadjusted poverty rate is the total poverty rate for that year. The adjusted poverty rate weights poverty for each family type by the average share of persons in that family for the six years indicated.

explained by these changes; changing family structure, however, does not appear to explain poverty trends in the 1960s or 1980s.

We also explore whether the increase in family income inequality documented earlier is affected by adjustments for family size. To examine this, we compare the unadjusted family income shares with a measure of 
family income divided by the equivalence scale implicit in the official poverty threshold. We term this measure adjusted family income. ${ }^{21}$ Table 5 shows the distribution of unadjusted and adjusted family income for persons in nonelderly families. These data show that family composition has played a relatively minor role in the changing income distribution: the family-size adjustment reduces some of the perceived equality in the 1960 s, but there is very little adjustment in the 1980s. Using both measures, family income inequality increased substantially in the early $1980 \mathrm{~s}$ but displays virtually no trend thereafter. This is in marked contrast to the substantial increase in the relative income of the poor in the expansion of the 1960s, which was found using both unadjusted and adjusted income. Furthermore, during the 1980 s family income inequality expanded within each of the family types listed in table 3 .

\section{Wage and Nonwage Income Inequality}

Much recent work has documented substantial increases in wage inequality among both males and females during the $1980 \mathrm{s.}^{22}$ Annual, weekly, and hourly earnings inequality all increased for males from the late 1970 s to the late $1980 \mathrm{~s} .{ }^{23}$ The log wage differential between workers at the 90th and 10th percentiles of the male weekly wage distribution increased by 18 percent from 1979 to 1988 as the real weekly wages of workers at the 90 th percentile rose by 5 percent and the wages of those at the 10 th percentile fell by 12 percent. ${ }^{24}$

The wage distribution widened along three primary dimensions in the 1980s. First, education differentials increased substantially, particularly for younger workers. From 1979 to the late 1980s, the weekly earnings of young male college graduates (those with 1 to 10 years of labor market experience) increased by approximately 30 percent relative to those of young males with 12 or fewer years of schooling. Second, among the less educated the average wages of older workers increased relative to the

21. A number of authors (Lazear and Michael, 1988; Van der Gaag and Smolensky, 1982) have argued that the official equivalence scales do not accurately reflect family economies of scale. We have experimented with a variety of alternative equivalence measures, including a per capita measure, with similar results.

22. See Levy and Murnane (1991) for a comprehensive survey of the literature on changes in U.S. earnings inequality.

23. Juhn, Murphy, and Pierce (1991); Karoly (1990).

24. Karoly (1990, table B.2). 
Table 5. Distribution of Unadjusted and Adjusted Family Income, Nonelderly Families, Selected Years, 1963-89

Percent

\begin{tabular}{lrrrrrr}
\hline Income quintile & 1963 & 1969 & 1973 & 1979 & 1983 & 1989 \\
\hline Unadjusted family & income & & & & & \\
First (lowest) & 5.4 & 6.1 & 5.5 & 5.0 & 4.2 & 4.2 \\
Second & 12.8 & 12.9 & 12.5 & 12.0 & 11.0 & 10.8 \\
Third & 17.9 & 17.8 & 17.7 & 18.0 & 17.4 & 17.1 \\
Fourth & 23.8 & 23.5 & 23.8 & 24.6 & 24.8 & 24.6 \\
Fifth (highest) & 40.0 & 39.7 & 40.4 & 40.4 & 42.6 & 43.3 \\
Adjusted family income & & & & & & \\
First (lowest) & 5.1 & 5.9 & 5.5 & 5.2 & 4.3 & 4.2 \\
Second & 11.9 & 12.2 & 12.1 & 12.1 & 11.0 & 10.8 \\
Third & 17.2 & 17.2 & 17.2 & 17.6 & 17.2 & 16.9 \\
Fourth & 23.6 & 23.4 & 23.5 & 24.4 & 24.5 & 24.2 \\
Fifth (highest) & 42.2 & 41.3 & 41.5 & 40.7 & 43.0 & 43.9 \\
\hline
\end{tabular}

Source: Authors' calculations based on data from the March CPS. Families headed by an elderly person are excluded from the sample. All distributions are weighted using person weights. Adjusted family income is family income divided by the equivalence scale implicit in the federal poverty thresholds after 1981 .

wages of younger workers. Third, earnings inequality increased within narrowly defined demographic and skill groups. ${ }^{25}$ The growth in wage differentials among education groups represented a break from the declining college wage premiums of the 1970s. The growth of within-group wage differentials in the 1980s appears to continue a pattern begun about 1970.

We assess whether these increases in wage inequality can account for observed changes in the family income distribution in the 1980s. An increase in the dispersion of the wages of primary earners directly increases family income inequality. Increased wage inequality among household heads may also have important indirect effects. First, to the extent that more than one person in the family works, movements of wages for primary earners may be offset or reinforced by the laborsupply responses of other family members. If income effects dominate family labor-supply decisions, one might expect increased market labor supply by other family members when the household head's earnings decline. Alternatively, positive assortive mating on earnings capacity,

25. See Blackburn, Bloom, and Freeman (1990), Bound and Johnson (1989), Katz and Murphy (forthcoming), and Murphy and Welch (forthcoming) for detailed analyses of changes in education and experience differentials. Juhn, Murphy, and Pierce (1991) discuss the rise in within-group inequality. 
Table 6. Distribution of Adjusted Family Income by Source of Income, Nonelderly Families, Selected Years, 1963-89

Percent

\begin{tabular}{lrrrr}
\hline Income quintile & 1963 & 1969 & 1979 & 1989 \\
\hline Earnings of primary earner & & & & \\
First (lowest) & 4.7 & 5.3 & 4.3 & 3.7 \\
Second & 12.8 & 12.9 & 12.8 & 11.4 \\
Third & 18.4 & 18.1 & 18.6 & 17.6 \\
Fourth & 24.2 & 23.6 & 24.7 & 24.6 \\
Fifth (highest) & 39.9 & 40.1 & 39.6 & 42.6 \\
Total labor income & & & & \\
First (lowest) & 4.3 & 4.8 & 3.9 & 3.3 \\
Second & 11.9 & 12.2 & 11.9 & 10.6 \\
Third & 17.4 & 17.5 & 18.0 & 17.3 \\
Fourth & 24.2 & 23.9 & 25.2 & 25.0 \\
Fifth (highest) & 42.3 & 41.6 & 41.0 & 43.9 \\
Total family income & & & & \\
First (lowest) & 5.1 & 5.9 & 5.2 & 4.2 \\
Second & 11.9 & 12.2 & 12.1 & 10.8 \\
Third & 17.2 & 17.2 & 17.6 & 16.9 \\
Fourth & 23.6 & 23.4 & 24.4 & 24.2 \\
Fifth (highest) & 42.2 & 41.3 & 40.7 & 43.9 \\
\hline
\end{tabular}

Source: Authors' calculations based on data from the March CPS. The table shows the distribution of adjusted income among quintiles of the nonelderly population. All distributions are weighted using person weights. Families are classified on the basis of total adjusted family income. Adjusted family income is family income divided by the equivalence scale implicit in the federal poverty thresholds after 1981.

and other factors causing positive correlation in market opportunities, may mean that income earned by secondary workers actually increases family income inequality during periods of a widening wage structure. McKinley Blackburn and David Bloom, for example, find that the correlation between husbands' and wives' earnings increased from 1979 to 1987 , implying that changes in family inequality will be greater than changes in male earnings alone. ${ }^{26}$ Second, because, as discussed earlier, the share of nonlabor income in market-based family income increased in the 1980s, we examine the importance of labor and nonlabor income in explaining increases in family income inequality.

Table 6 presents evidence on the importance of different sources of earnings in explaining increased family income inequality. Given the disparity between nonelderly and elderly families, we focus on the non-

26. Blackburn and Bloom (1991a). 
Figure 6. Components of Change in the Share of Family Income of the Lowest Quintile, Nonelderly Population, Selected Intervals, 1963-89

Percentage points

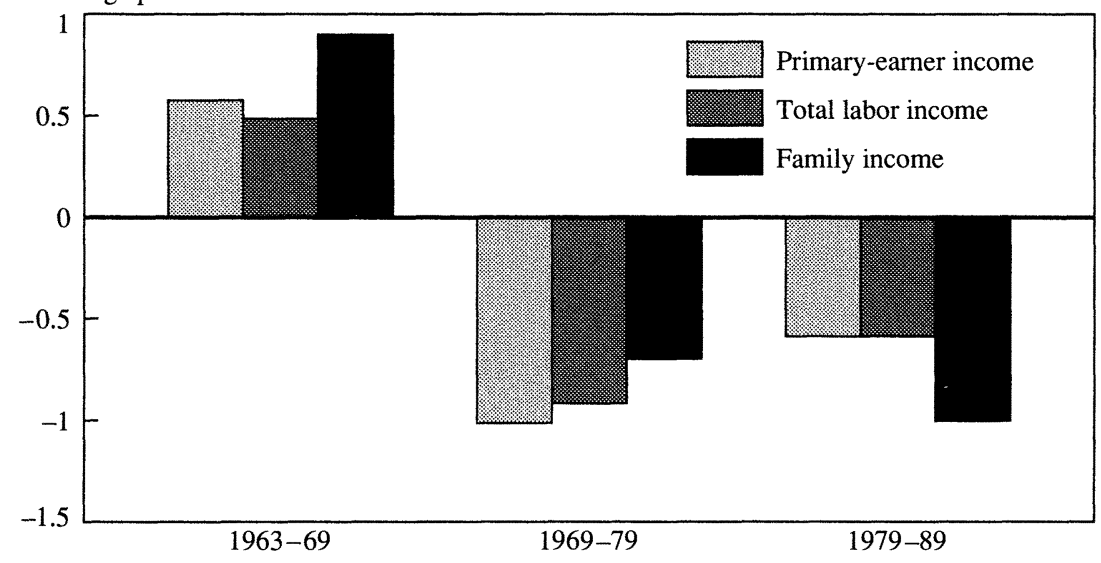

Source: See table 6 .

elderly population. We define primary-earner income for each family as the total earnings of the person with the maximum earnings in the family.$^{27}$ We adjust primary-earner income for family composition using the family equivalence scale described above. On average, primary-earner income is about 70 percent of total family income.

The upper panel of table 6 shows the distribution of primary-earner income for 1963, 1969, 1979, and 1989 using the quintiles of the family income distribution. There is a clear trend toward increased inequality since the late 1960s, consistent with the evidence we have been discussing. The lowest quintile of the family income distribution gained 0.6 percentage point from 1963 to 1969 because of changes in the distribution of the earnings of primary earners. Changes in the labor market outcomes of primary earners worked against the lowest quintile in the 1970s and 1980 s, even adjusting for the change in family size. The effect of primary earners on the income share of the lowest quintile is depicted in figure 6 (the first set of bars).

To examine the role of secondary earners in changing the family income distribution, table 6 also shows the distribution of total labor income, using the quintiles of the family income distribution. The differ-

27. Total earnings equal the sum of wage and salary income, nonfarm self-employment income, and farm self-employment income. 
ence between the middle panel and the upper panel, then, is the effect of additional earners on the income distribution. On average, this income accounts for about 20 percent of total family income. At any given point in time, income from secondary workers increases the disparity of the income distribution relative to that disparity generated by primary earners alone. The share of income going to the lowest quintile of the income distribution falls by about one-half of one percentage point when additional labor income is included. Accounting for changes in the distribution of this income, however, slightly reduces the disparity of changes in income between the 1960s and 1980s. The middle set of bars in figure 6 shows that changes in the distribution of total earnings reduced the shares of the lowest quintile in the 1960s and 1970s and had little effect on the distribution of income in the 1980s.

The final panel of table 6 further expands the measure of income to total family income, a measure similar to that used in table 5 . The difference between labor income and family income, about 10 percent of family income, is predominantly transfers and capital income. Accounting for nonlabor income reduces the inequality of family income generated by labor income, reflecting the importance of transfers in the lowest income levels. However, changes in the distribution of nonlabor income had very different effects. As the last set of comparisons in figure 6 indicates, changes in nonlabor income had large equalizing effects in the 1960s and 1970s, but then skewed toward the higher income groups in the 1980s. These shifts reflect a decline in transfer payments to the nonelderly relative to other nonlabor income. The share of income to the poorest 20 percent of the primary-earner distribution falls an additional 0.4 percentage point between 1979 and 1989 when nonlabor income is taken into account.

Although secondary-earner income and nonlabor income are both important in accounting for increased family income inequality, figure 6 shows that the dominant source of change in family income inequality has come from shifts in the distribution of primary-earner income. While increased inequality in labor earnings is thus the most important contributor to increased family income inequality in the 1980s, other research has shown that declines in transfer payments to families at the lower end of the income distribution have played a substantial role in increasing poverty rates, particularly for female-headed households. ${ }^{28}$

28. See, for example, Hanratty and Blank (forthcoming) and Mishel and Frankel (1991). 


\section{Is Rising Inequality an Illusion? A Look at Consumption}

In the two previous sections on inequality and material hardship, as in most work on the level and distribution of economic well-being, we have used readily available statistics on money income. Measures of inequality and poverty based on pretax, post-transfer income indicate substantial changes in income inequality and persistent poverty in the United States during the 1980s, a development that represents a sharp break from the postwar pattern. These changes are not solely due to compositional shifts in the structure of families or changes in the form of received income. Further, other research has shown that the inequality of post-tax, pretransfer income also increased during the $1980 \mathrm{~s},{ }^{29}$ suggesting that changes in tax policy are not compensating for the change in pretax income. Thus, if money income is a reasonable proxy for access to material resources, little progress has been made in the war on poverty since the early 1970 s.

Various objections have been voiced, however, concerning the use of poverty measures based on annual money income. First, such measures may fail to capture income received through in-kind transfers, a particularly important problem for the measurement of poverty since families with low money incomes often receive a variety of in-kind transfers including food stamps, housing assistance, and medicaid. Many of these programs expanded rapidly in the 1970 s, suggesting that official poverty rates overstate the level of and exaggerate the increases in poverty during the 1970s. Nevertheless, since such programs did not expand greatly during the 1980s, our inferences concerning changes in poverty in the 1980 s are unlikely to be affected by imputing a value to in-kind transfers. A consistent poverty rate series that includes estimates of the value of in-kind income and noncash transfers (including food stamps and housing and medical assistance) is available for the 1979-87 period and can be used to assess the importance of this income. ${ }^{30}$ While the official poverty rate increased by 1.7 percentage points (from 11.7 to 13.4 percent) between 1979 and 1987, the adjusted rate increased by a slightly larger 2.1 percentage points (from 8.9 to 11.0 percent).

Second, it is well known that income underreporting is a problem in household surveys, and some researchers have speculated that families

29. Gramlich, Kasten, and Sammartino (1990).

30. McNeil (1988). 
have become increasingly likely to underreport income. Growth in illegitimate income and means-tested transfers may have led to an increased underreporting of income, particularly among the disadvantaged. ${ }^{31}$

Furthermore, economic theory does not provide a strong case for the use of annual income to assess economic welfare. The life-cycle-permanent-income hypothesis strongly suggests that permanent income is a more accurate gauge of economic welfare than is current income. Increases in the variance of transitory income shocks could lead to an increase in the variance of reported current income with little change in the distribution of permanent economic status. If consumers do follow the life-cycle-permanent-income model, then consumption provides a more accurate picture of permanent income and material welfare than does current income. Changes in relative prices may also differentially affect the poor and nonpoor. In this case, measures of real income that use aggregate deflators, such as the CPI or PCE implicit price deflator, may yield a distorted picture of changes in living standards for groups whose consumption baskets are different from the "aggregate" bundles used in the deflators. An increase in the aggregate price level associated with an increase in the price of necessities relative to luxuries, for example, will increase the level of "true poverty" compared with the same aggregate price increase associated with a relative increase in the price of luxuries. Finally, standard income statistics fail to capture disparities in consumption arising from differences in financial wealth, in stocks of consumer durables, and in access to credit.

The use of income-based measures of inequality and poverty has come under attack by those who believe that they inaccurately measure economic inequality and material hardship. Jencks has presented a collage of evidence indicating that the decade of the 1970s was a period of "hidden prosperity," with substantial improvements in average living standards and reductions in the material hardship of the poor, neither of which is captured in income statistics. In addition, Mayer and Jencks present survey evidence for a sample of households in Chicago, showing

31. Mayer and Jencks (1991). See Lillard and Smith (1986) for a detailed discussion of income underreporting in the Census of Population and Current Population Survey. In fact, the Census Bureau reports that changes in processing have increased the share of aggregate income captured by the CPS in recent years; see Bureau of the Census (1989, p. 16). 
that income-based indicators of poverty are only weakly correlated with many "direct" measures of material hardship. ${ }^{32}$ They argue further that examination of other measures of living standards (like crowding, the adequacy of housing conditions, and access to medical care) reveals no increase in inequality from the early 1970 s to the mid-1980s. ${ }^{33}$ Dale Jorgenson, too, in a carefully formulated economic framework, has demonstrated that economic welfare is more accurately captured by consumption than by income. ${ }^{34}$ In further work, Daniel Slesnick has used this framework to show that income-based measures provide "severely biased" measures of the level and trend of U.S. poverty and economic inequality. ${ }^{35}$ This literature suggests that increased income inequality and poverty in the 1970s and 1980s may reflect the weak link between income measures and actual material well-being, rather than a substantive change in the ability of the disadvantaged to benefit from general economic growth. Thus, we now examine changes in the distribution of consumption using micro data from the Consumer Expenditure Surveys covering the past thirty years.

\section{The Consumer Expenditure Survey Data}

Household-level data on expenditures and income over the course of a year are available in reasonably consistent form for scattered dates over the past three decades from the Consumer Expenditure Surveys. The CES is a large-scale household survey that attempts to gather detailed information on the expenditure patterns of the typical household and is used to derive expenditure weights for the consumer price index. In the past, the CES had been conducted approximately every ten years, starting in the early 1900 s and ending in 1980 . Since 1980 , it has been conducted on a continuous basis. ${ }^{36}$

We utilize public-use micro data from the CES for 1960-61, 1972-73, 1980,1984 , and 1988 to measure changes in the distribution of consumption. The unit of observation in these surveys is what the Bureau of La-

32. Jencks (1984); Mayer and Jencks (1989).

33. Mayer and Jencks (1991).

34. Jorgenson (1990).

35. Slesnick (1991c, 1991d).

36. See Jacobs and Shipp (1990) for a discussion of the historical evolution of the expenditure survey methodology. 
bor Statistics (BLS) calls a consumer unit. A consumer unit is a group of individuals who live in the same household and either are related or share in at least two of the three major expense categories: housing, food, and other living expenses. ${ }^{37}$ Our goal in the design of samples and the construction of consumption measures has been to make them as comparable over time as possible. Since the information provided by the CES has changed over time, the goal has necessitated discarding potentially useful information that is available in some years but not in others. A detailed description of our sample-selection criteria and the construction of key variables is presented in the appendix.

We examine two basic measures of consumption. The first, which we denote as total expenditures, is the direct measure of total consumer spending over the course of a year. Total expenditures include all direct out-of-pocket expenditures made by consumer units. These include all direct purchases of goods and services, insurance payments (including employee social security and retirement contributions), and cash contributions. Indirect purchases such as employer-provided health and life insurance benefits are not included.

As a measure of economic consumption, total expenditures presents several problems. Possibly the most important problem is the treatment of consumer durables. All current out-of-pocket expenditures on consumer durables, including purchases of new and used durable goods, are included as current consumption expenditures in the CES. Current outof-pocket expenditures may therefore provide an inaccurate picture of the service flow provided by a consumer unit's stock of consumer durables. The most important expenditure items for which this difficulty exists are housing and motor vehicles. Total expenditures include mortgage payments for homeowners with mortgages but exclude the consumption value of the house for those consumer units without mortgages. This measure is likely to be particularly misleading for consumer units who have no mortgage or who are close to owning their house outright, such as the elderly. Similarly, spending on new automobiles is included in expenditures, but the consumption value of the existing stock is not.

A second potential difficulty with the use of total expenditures as a consumption measure is that expenditures on insurance-particularly

37. Bureau of Labor Statistics (1985, p. 131). 
life insurance payments, employee social security contributions, and other pension contributions-are treated as part of current consumer expenditures. Many of these payments can be viewed conceptually, however, as savings or tax payments rather than as current consumption.

These difficulties with total expenditures as a measure of economic resources motivate our use of a second consumption measure, which we denote total consumption. Total consumption is formed from total expenditures in two steps. We first subtract spending on insurance, pensions, and social security. The second adjustment to consumption is to exclude spending on the two largest categories of consumer durablesowned homes and new and used vehicles-and to impute a rental equivalence for each. For the homeowner adjustment, we subtract payments of mortgage principal and interest from consumption and add a rental equivalence measure imputed from self-reported data on market values; the appendix describes the procedure in detail. For the vehicle adjustment, we exclude spending on new and used vehicles and include an estimate of the consumption value of the stock of existing vehicles. The consumption value is the predicted purchase price of a new vehicle for each household times the number of existing vehicles the household owns, times an assumed annual rate of depreciation (one-eighth of the value each year). The appendix also describes this adjustment in more detail. ${ }^{38}$

A potentially important issue concerning the CES data is the possibility of systematic changes over time in the level of underreporting of income and expenditure. The emphasis in CES interviews is on gathering expenditure information rather than on gathering detailed information on sources of income. The expenditure data are generally believed to be of higher quality than the income information in the CES. We compare CES and CPS income data in the appendix and conclude that CES data closely approximate CPS data in 1972-73 but that income underreporting in the CES relative to the CPS increased substantially in the 1980s. Comparisons of CES expenditure data with NIA data on consumer expenditures also suggest a possible deterioration in CES re-

38. Slesnick (1991a) adjusts consumption for additional durable goods items beyond housing and vehicles. Since housing and vehicles are the largest durable components and since the most complete data exist for these categories, we adjust only for these two components. 
porting from the 1970 s to the early 1980 s. ${ }^{39}$ The CES sampling framework and survey methodology are much more consistent over the 1980s than they are between the widely separated earlier surveys.

One final issue that arises with data on consumer units is that the size of consumer units has declined over the course of the surveys. As with our income measures in the previous section, we report results using the household equivalence scale implicit in the federal poverty level. We have examined a variety of different equivalence scales, however, and found that our qualitative results are not very sensitive to assumptions about household economies of scale or assumptions about the relative needs of children and adults. ${ }^{40}$

In conclusion, the problems with income data in the CES lead us to use income data from the CPS as our primary measure of income inequality. For consumption measures, although one must be cautious in interpreting changes in consumption levels because of the potential deterioration in survey quality, the CES provides the only reasonably consistent data to examine changes in the distribution of consumption over time.

\section{Income, Expenditures, and Consumption in Cross Section}

We first examine differences in the distribution of income, total expenditures, and total consumption at a single point in time. Table 7 shows statistics on the 1988 levels and distribution of income, expenditures, and consumption using both CES and CPS measures. The top panel of the table displays the mean per capita levels of each variable for the entire sample and for children (persons below age 18), adults (persons aged 18 to 64), and the elderly (persons age 65 and over). We do not attempt to apportion income or consumption across the family members. Thus, the income of a child, for example, is total consumer unit income divided by the number of persons in that consumer unit or family.

The bottom panel of the table shows the distribution of each variable

39. Bosworth, Burtless, and Sabelhaus (1991); Sabelhaus (1990); Slesnick (1991b).

40. By contrast, Slesnick (1991c, 1991d) finds that trends in poverty and inequality measures may be quite sensitive to the choice of equivalence scale when one allows the needs of consumer units to depend on the race, sex, and age of the household head as well as on the region of residence and type of residence (farm or nonfarm). 
Table 7. Distribution of Income, Expenditures, and Consumption, per Capita, 1988

\begin{tabular}{|c|c|c|c|c|c|}
\hline \multirow[b]{2}{*}{ Income group } & \multirow[b]{2}{*}{$\begin{array}{c}\text { CPS } \\
\text { pretax } \\
\text { income }\end{array}$} & \multicolumn{4}{|c|}{$C E S$} \\
\hline & & $\begin{array}{l}\text { Pretax } \\
\text { income }\end{array}$ & $\begin{array}{c}\text { Adjusted } \\
\text { income }^{\mathrm{a}}\end{array}$ & $\begin{array}{c}\text { Total } \\
\text { expendi- } \\
\text { tures }\end{array}$ & $\begin{array}{c}\text { Total } \\
\text { consump- } \\
\text { tion }\end{array}$ \\
\hline \multicolumn{6}{|c|}{ Mean amounts (1988 dollars) } \\
\hline All & 12,908 & 11,379 & 14,341 & 9,788 & 9,402 \\
\hline Adults & 14,824 & 13,189 & 16,420 & 11,053 & 10,324 \\
\hline Elderly & 12,790 & 10,447 & 14,531 & 9,862 & 11,594 \\
\hline Children & 8,429 & 7,744 & 9,589 & 6,915 & 6,330 \\
\hline \multicolumn{6}{|c|}{ Distribution by decile (percent) } \\
\hline First (lowest) & 1.1 & 1.3 & 1.4 & 2.0 & 2.2 \\
\hline Second & 3.0 & 2.9 & 3.0 & 3.6 & 4.0 \\
\hline Third & 4.4 & 4.2 & 4.5 & 5.0 & 5.4 \\
\hline Fourth & 5.7 & 5.5 & 5.9 & 6.1 & 6.7 \\
\hline Fifth & 7.1 & 6.9 & 7.4 & 7.3 & 7.9 \\
\hline Sixth & 8.6 & 8.5 & 8.8 & 8.7 & 9.2 \\
\hline Seventh & 10.5 & 10.4 & 10.6 & 10.4 & 10.8 \\
\hline Eighth & 13.0 & 12.9 & 13.0 & 12.6 & 12.7 \\
\hline Ninth & 17.0 & 17.0 & 16.6 & 16.2 & 15.8 \\
\hline Tenth (highest) & 29.6 & 30.3 & 28.8 & 28.2 & 25.3 \\
\hline Gini coefficient & .423 & .427 & .408 & .384 & .348 \\
\hline
\end{tabular}

Sources: Authors' calculations based on data from the 1988 Consumer Expenditure Survey (CES) and the March 1989 CPS. Mean amounts are weighted by the number of persons in each group. Children are persons less than 18 years old; adults are aged 18-64; elderly are aged 65 and above. Decile distributions are sorted by the variable whose shares are reported.

a. Adjusted income is pretax income plus the rental equivalence of owner-occupied housing and owned vehicles.

for the entire population. Here, we treat each variable separately, so that, for example, the shares of income are for families in each decile of the income distribution and the shares of expenditures are for consumer units in each decile of the expenditure distribution. We also present Gini coefficients to summarize the degree of inequality in the distributions for each variable.

The first column of the table provides information on per capita income from the CPS; the second column provides similar information from the CES. Both columns indicate that mean income is highest for nonelderly adults and lowest for children. The substantial underreporting of income in the CES relative to the CPS in 1988 is also apparent from the two columns. The distributions of income are fairly similar in the two surveys, however. If underreporting of income and consumption is similar, our distributions of both variables across subgroups will be correct even if the levels are not. 
The third column displays "adjusted" income from the CES. Adjusted income adds imputed rental income from owned houses and vehicles to pretax money income. These income imputations raise the relative income of the elderly and reduce dispersion in the overall income distribution. Although the Gini coefficient falls fairly substantially using this measure, most of the changes are due to increased income in the middle deciles and away from the upper deciles. The share of adjusted income received by the poorest quintile is similar to the share without the income adjustment.

The fourth column of table 7 reports total expenditures per capita. Mean expenditures are much more equal across groups than are any of the income measures. The data reflect positive savings for all ages, though the differential between income and expenditures is smallest for the elderly.

The final column examines the distribution of total consumption. There is a striking difference between the elderly and the nonelderly when comparing expenditure and consumption, with a much higher living standard for the elderly using the total consumption measure. The average difference between the consumption and expenditure of the elderly is $\$ 1,732$ (17.5 percent of expenditures); by contrast, consumption is somewhat lower than expenditure for the nonelderly. The principal reasons for these differences between the elderly and nonelderly are the housing and insurance adjustments. Since many of the elderly own their own homes, often without mortgages, elderly consumption is dramatically increased by our rental imputation. For the nonelderly, however, the housing adjustment raises the mean by a small amount $(\$ 361)$; the adjustment for vehicles has almost no effect on the mean; and the exclusion of insurance payments (predominantly employee contributions for social security) substantially reduces the mean. These insurance payments and taxes averaged $\$ 1,066$ per capita for the nonelderly in 1988 .

The lower panel of table 7 also shows substantial differences in the distributions of income, expenditure, and consumption. The distribution of expenditures is clearly more equal than the distribution of income, and consumption is even more equally distributed than expenditures. While the lowest quintile of the income distribution received only 4.1 percent of total money income in 1988 , the lowest quintile of the expenditure distribution accounted for 5.6 percent of total expenditures and the lowest quintile of the consumption distribution accounted for 6.2 
percent of total consumption. The smaller degree of dispersion in consumption than in expenditures and in expenditures than in income is also true within all the age groups. All three of the adjustments to total expenditures used to form total consumption contribute to the 9.4 percent decline in the Gini coefficient between the expenditures and consumption measure.

\section{The Distribution of Income and Consumption, 1960-88}

The distributions of income, total expenditures, and total consumption differ substantially in any year, as predicted by the life-cycle-permanent-income hypothesis. But this finding does not necessarily imply that secular changes in the distribution of current income are a misleading measure of changes in material well-being. To examine this issue, we compare changes in the distributions of adjusted family income, consumption, and expenditures across the past thirty years. The adjustments in this case use the family equivalence scales in the federal poverty measure.

Tables 8 and 9 present information on changes in the distribution of pretax, post-transfer money income and total expenditures per equivalent person over the past thirty years from the CPS (table 8) and CES (table 9). ${ }^{41}$ Information for all individuals is presented in the upper panels of each table and for those living in nonelderly households in the lower panels.

The two tables reveal similar patterns of change in the distribution of income and expenditures. Table 8 reiterates the basic facts on decreased income inequality in the 1960 s and increased inequality since that period. Table 9 shows that these patterns are as true for expenditure-based measures of inequality as they are for income-based measures. For the poor, expenditures per equivalent person grew in the 1960s expansion, both in absolute terms and as a share of total expenditures. The expenditure distribution widened during the 1980s, however. The share of total expenditures going to the lowest quintile declined from 7.5 percent to 6.5 percent between 1980 and 1984, reflecting the severe recession of the

41. We summarize changes in the income, expenditures, and consumption distributions by reporting decile shares and mean levels within deciles. Our qualitative results are similar if we examine levels of each variable at each percentile. Our results are not driven by outliers at the top and bottom of the distribution. 


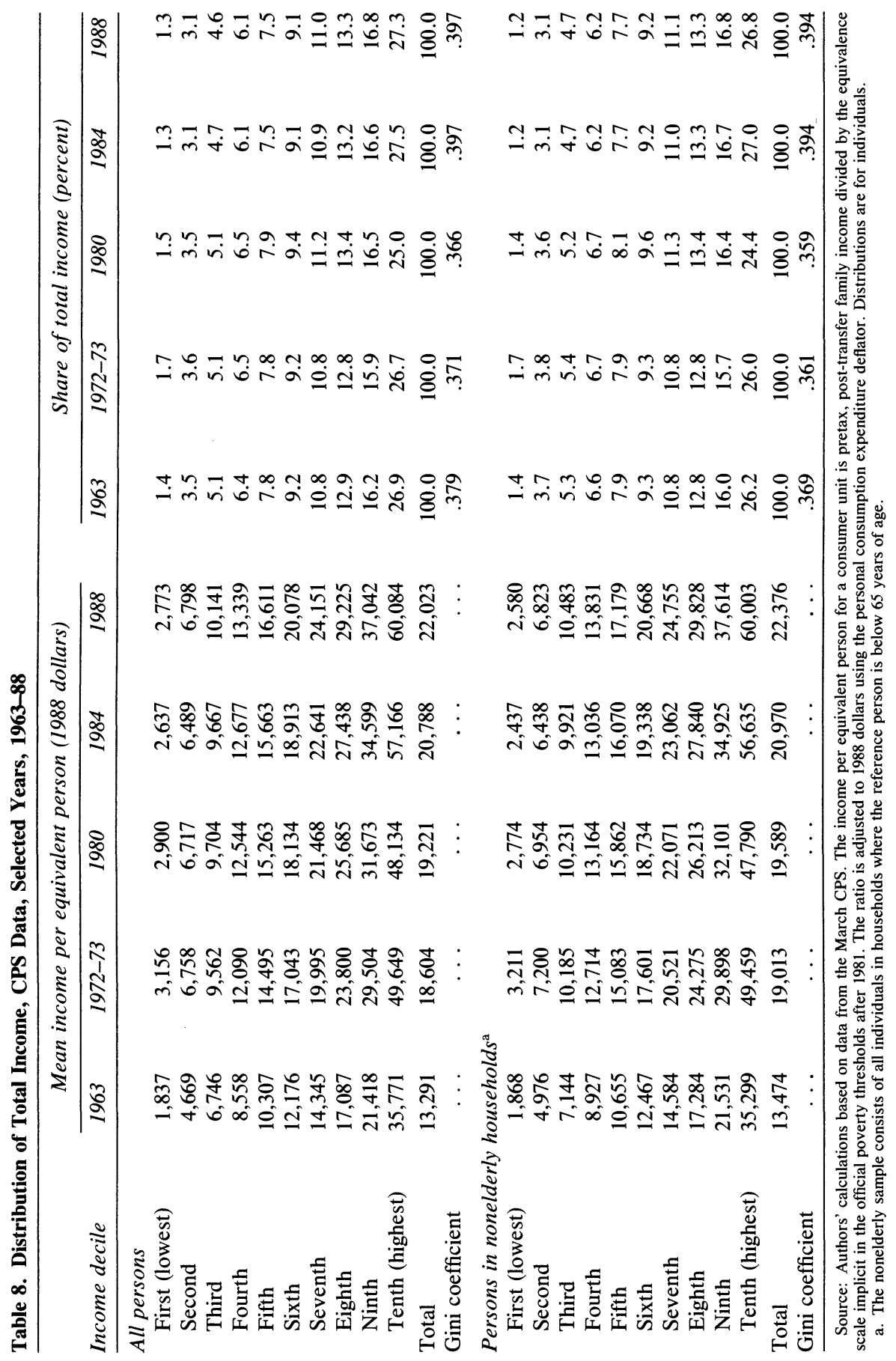




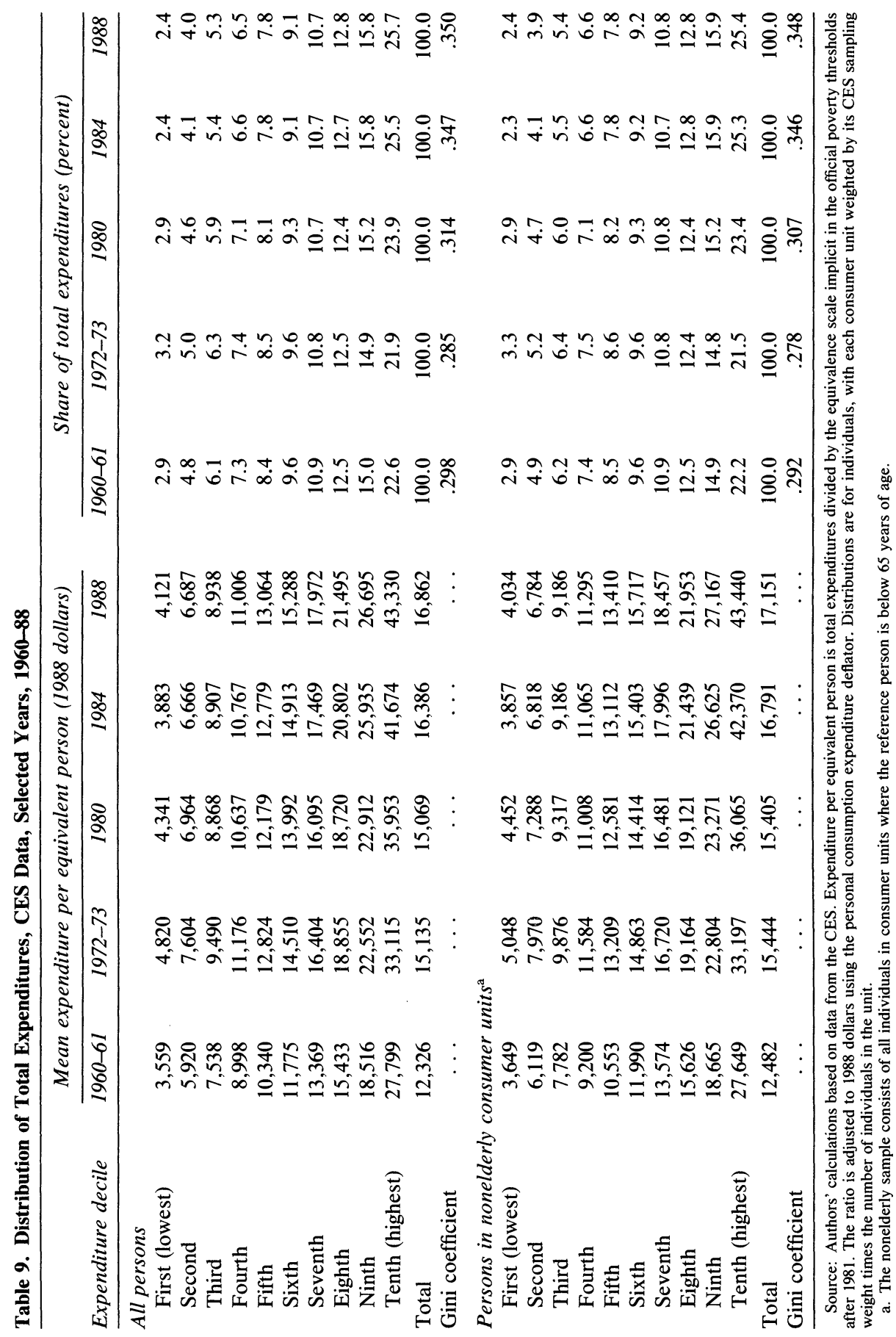


early 1980s. What is more noticeable, however, is the further slight decline in the share of total expenditures going to the bottom quintile during the robust macroeconomic recovery of 1984-88. Thus, using both income and expenditure measures, we find the share of resources going to the poor did not increase as the macroeconomy boomed. Overall, expenditures and income both indicate increased inequality and material hardship in the 1980s.

The breakdown in the relationship between macroeconomic performance and the disadvantaged, we have already shown, holds largely for working-age families. The lower panels of tables 8 and 9 , therefore, report changes in income and expenditures among nonelderly households. Among this group, the pattern of rising inequality in income and expenditures in the 1980 s is even more striking. The share of total expenditures going to the bottom decile declined by more than one-fifth from 1980 to 1988 .

Given the problems with total expenditures as a measure of economic consumption, table 10 examines changes in the distribution of total consumption. A comparison of table 10 with table 9 highlights the similarity of the changes in the distribution of the two variables. Consumption inequality was greatly reduced from the early 1960 s to the early 1970 s, along with expenditure inequality, and then increased in the 1970s and 1980s. Although the increase in inequality is slightly moderated in the consumption distribution, it is still substantial. Further, the expansion from 1984 to 1988 does not appear to have reduced consumption inequality at all.

Jorgenson and Slesnick both raise the possibility that relative price changes may have important effects on the poor relative to the rich. ${ }^{42}$ In this case, our total consumption measure may provide an inaccurate guide to changes in the actual consumption of different groups of the population. To explore this issue, we have constructed an alternative consumption measure in which we break down total consumption into 12 major expenditure categories and use the consumer price indexes for specific expenditure classes to convert expenditures into 1988 dollars. ${ }^{43}$

42. Jorgenson (1990); Slesnick (1991a, 1991d).

43. The 12 categories used are food and alcohol; apparel; shelter; fuels, utilities, and public services; household operations; house furnishings and equipment; vehicles; other transportation expenses; health care; entertainment; cash contributions; and all other goods and services. We use the category-specific consumer price indexes to deflate ex- 


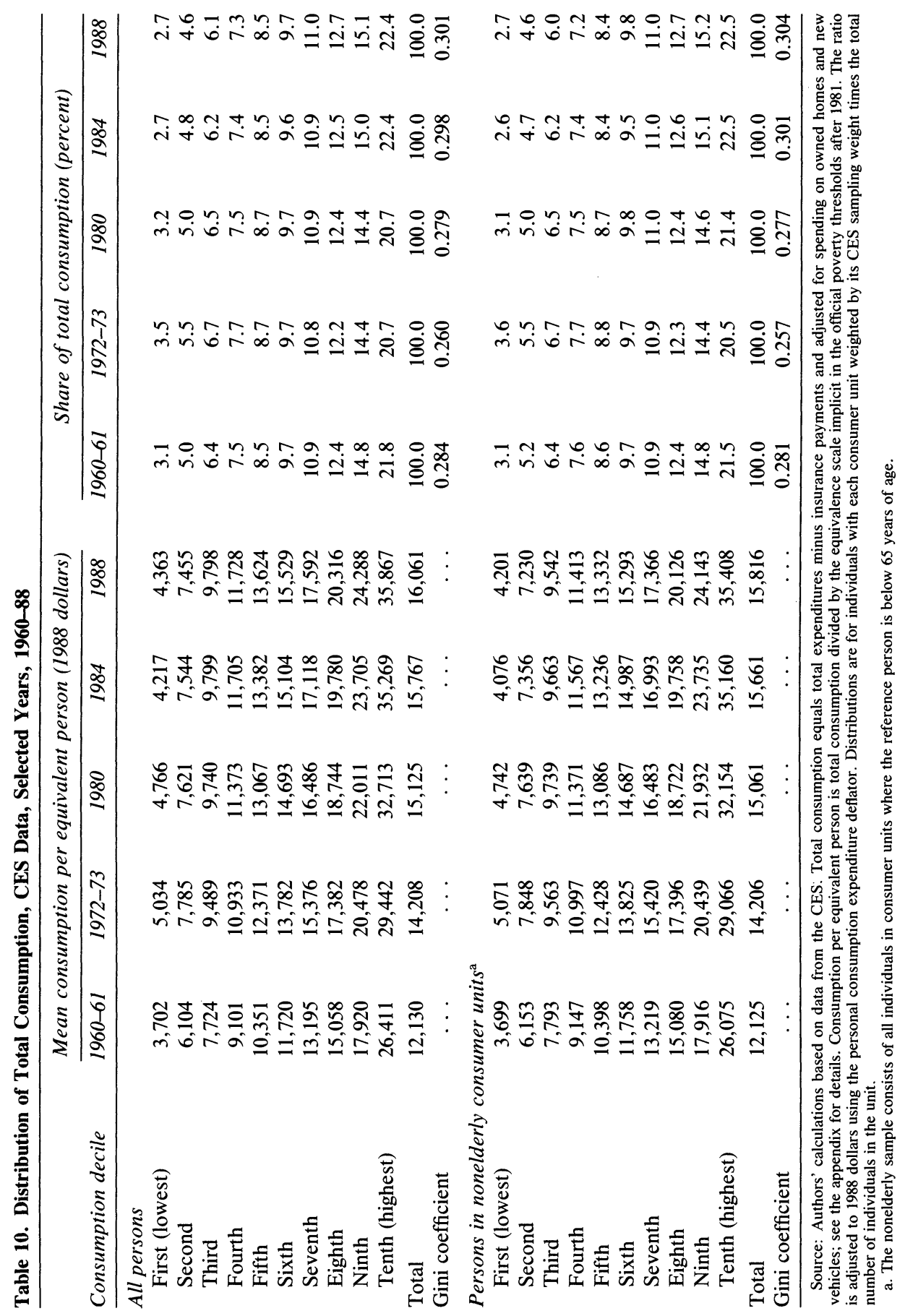


We refer to this variable as component-deflated consumption. Table 11 presents changes in the level and distribution of our component-deflated consumption measure. The table indicates that the pattern observed in the previous tables in this section remains essentially unchanged when one takes into account relative price changes. ${ }^{44}$ Inequality in component-deflated consumption decreased in the 1960s and expanded during the $1980 \mathrm{~s}$.

To avoid the imputations inherent in our measure, we have also examined a measure of nondurable consumption, excluding housing costs, new vehicle purchases, insurance payments, and spending on major appliances. Our findings concerning changes in the distribution of consumption over time are quite similar to those reported in tables 9,10 , and 11 when we use this measure of consumption of nondurables. Increased consumption inequality in the 1980 s is not driven by our imputations for durables.

\section{Can Income Still Measure Economic Well-Being?}

Trends in consumption across deciles have mirrored trends in income throughout the post-1960 period. That evidence does not address the relation between income and consumption at the micro level, however. One argument against using income measures to determine poverty rates, for example, is that for any given family, current income is a misleading indicator of true economic status. James Poterba finds, using the 1985 CES, that 15 percent of the consumer units in the lowest income decile are above the third expenditure decile, as are 28 percent of the consumer units in the second income decile. ${ }^{45}$

To examine whether the relation between income and consumption has deteriorated over time, we consider the correlation between the two

penditures, with the exception of cash contributions, where we use the overall CPI. The indexes used are from the Economic Report of the President 1991, tables B-59 and B-60. For 1960-61 and 1972-73, the deflation is, necessarily inexact, since the definition of consumption categories has changed over time. We attempt to produce the same groups in all years, however, using the concordances in Bureau of Labor Statistics $(1978,1985)$.

44. Slesnick (1991c, 1991d) similarly finds that taking into account relative price changes has little effect on inferences concerning changes in poverty and inequality.

45. Poterba (1991). 
Table 11. Distribution of Component-deflated Consumption for Nonelderly Consumer Units, CES Data, Selected Years, 1960-88

\begin{tabular}{|c|c|c|c|c|c|}
\hline Consumption decile & $1960-61$ & $1972-73$ & 1980 & 1984 & 1988 \\
\hline \multicolumn{6}{|c|}{ Mean consumption per equivalent person (1988 dollars) } \\
\hline First (lowest) & 3,594 & 4,991 & 4,719 & 4,048 & 4,201 \\
\hline Second & 5,960 & 7,753 & 7,616 & 7,303 & 7,230 \\
\hline Third & 7,575 & 9,467 & 9,676 & 9,543 & 9,542 \\
\hline Fourth & 8,883 & 10,851 & 11,280 & 11,437 & 11,413 \\
\hline Fifth & 10,084 & 12,225 & 12,918 & 13,027 & 13,332 \\
\hline Sixth & 11,362 & 13,549 & 14,539 & 14,732 & 15,293 \\
\hline Seventh & 12,759 & 15,076 & 16,253 & 16,691 & 17,366 \\
\hline Eighth & 14,523 & 16,971 & 18,398 & 19,296 & 20,126 \\
\hline Ninth & 17,167 & 19,782 & 21,568 & 23,111 & 24,143 \\
\hline Tenth (highest) & 24,832 & 27,267 & 31,274 & 34,040 & 35,408 \\
\hline Total & 11,674 & 13,835 & 14,824 & 15,333 & 15,816 \\
\hline Gini coefficient & $\ldots$ & $\ldots$ & $\ldots$ & $\ldots$ & $\ldots$ \\
\hline \multicolumn{6}{|c|}{ Share of total consumption } \\
\hline First (lowest) & 3.1 & 3.6 & 3.2 & 2.6 & 2.6 \\
\hline Second & 5.1 & 5.6 & 5.1 & 4.8 & 4.6 \\
\hline Third & 6.5 & 6.9 & 6.5 & 6.2 & 6.0 \\
\hline Fourth & 7.6 & 7.8 & 7.6 & 7.5 & 7.2 \\
\hline Fifth & 8.6 & 8.8 & 8.7 & 8.5 & 8.4 \\
\hline Sixth & 9.7 & 9.8 & 9.8 & 9.3 & 9.8 \\
\hline Seventh & 10.9 & 10.9 & 11.0 & 11.2 & 11.0 \\
\hline Eighth & 12.4 & 12.3 & 12.4 & 12.6 & 12.7 \\
\hline Ninth & 14.7 & 14.3 & 14.6 & 15.1 & 15.2 \\
\hline Tenth (highest) & 21.3 & 20.0 & 21.1 & 22.2 & 22.5 \\
\hline Total & 100.0 & 100.0 & 100.0 & 100.0 & 100.0 \\
\hline Gini coefficient & .277 & .250 & .273 & .297 & .304 \\
\hline
\end{tabular}

Source: Authors' calculations based on data from the CES. The table shows the distribution of consumption with the components individually deflated to 1988 dollars. See the appendix for details. The consumption per equivalent person for a consumer unit is total deflated consumption divided by the equivalence scale implicit in the official poverty thresholds after 1981. Distributions are for individuals, with each consumer unit weighted by its CES sampling weight times the total number of individuals in the unit. The nonelderly sample consists of all individuals in consumer units where the reference person is below 65 years of age.

in a series of cross sections, using the data in our CES surveys. ${ }^{46}$ If income has deteriorated as a measure of economic resources, the correlation between income and consumption should decline in the later surveys relative to earlier ones.

46. An alternative approach to this issue, which we do not pursue, involves estimating consumption functions at the individual level. Substantial recent research has shown, however, that only very restrictive sets of preferences will lead to consumption functions that can be estimated at the individual level. See Hall (1990) for more discussion. We thus pursue the less restrictive approach to the issue. 
Table 12. Correlation of Income with Consumption and Expenditures, Selected Years, 1960-88

Correlation coefficient

\begin{tabular}{lccccc}
\hline & \multicolumn{2}{c}{ Unadjusted } & & \multicolumn{2}{c}{ Adjusted } \\
\cline { 2 - 3 } \cline { 5 - 6 } Year & Expenditures & Consumption & & Expenditures & Consumption \\
\hline $1960-61$ & 0.889 & 0.874 & & 0.867 & 0.848 \\
$1972-73$ & 0.820 & 0.805 & & 0.758 & 0.732 \\
1980 & 0.741 & 0.720 & & 0.680 & 0.647 \\
1984 & 0.755 & 0.733 & & 0.714 & 0.685 \\
1988 & 0.759 & 0.743 & & 0.718 & 0.692 \\
\hline
\end{tabular}

Source: Authors' calculations based on data from the CES. The table shows the correlation between the logarithm of income and the logarithm of consumption or expenditures for various years. Adjusted figures are divided by the equivalence scale implicit in the official poverty thresholds after 1981.

Table 12 shows the correlation between the logarithm of income and the logarithm of our two consumption measures for each of the CES surveys ${ }^{47}$ The table suggests two contrasting conclusions. First, there is a decline in the predictive power of income in the later surveys relative to the previous ones. Using the adjusted measure of total consumption, for example, the correlation between income and consumption declined from 0.848 in $1960-61$, to 0.732 in $1972-73$, to about 0.690 in the $1980 \mathrm{~s}$. Since the quality of the CES appears comparable in the 1960-61 and 1972-73 periods, this suggests at least some decline in the extent of material hardship that is conveyed by changes in income. Because the quality of the CES data fell dramatically in the 1980s, however, it is difficult to determine whether the reduced correlation between 1972-73 and the 1980s results from less information about economic hardship in the income numbers or from increased measurement error.

The second conclusion from table 12 is that the correlation between income and consumption did not decline in the 1980 s, the period of the most dramatic changes in the income (and consumption) distributions. For all four measures of consumption, the correlation between income and consumption increases throughout the 1980s. At a minimum, this suggests that the trends in income inequality within the 1980s are having a greater effect on consumption over time.

47. The small number of consumer units that report nonpositive values of income and total consumption is dropped from the samples used for estimating the correlation coefficients. The basic pattern of findings in table 12 is almost identical when these observations are retained and correlations of the level of income and consumption are examined. 
Figure 7. Changes in Mean Consumption per Capita and Income per Capita by Demographic Group, $1980-88$

Log change in

consumption per capita

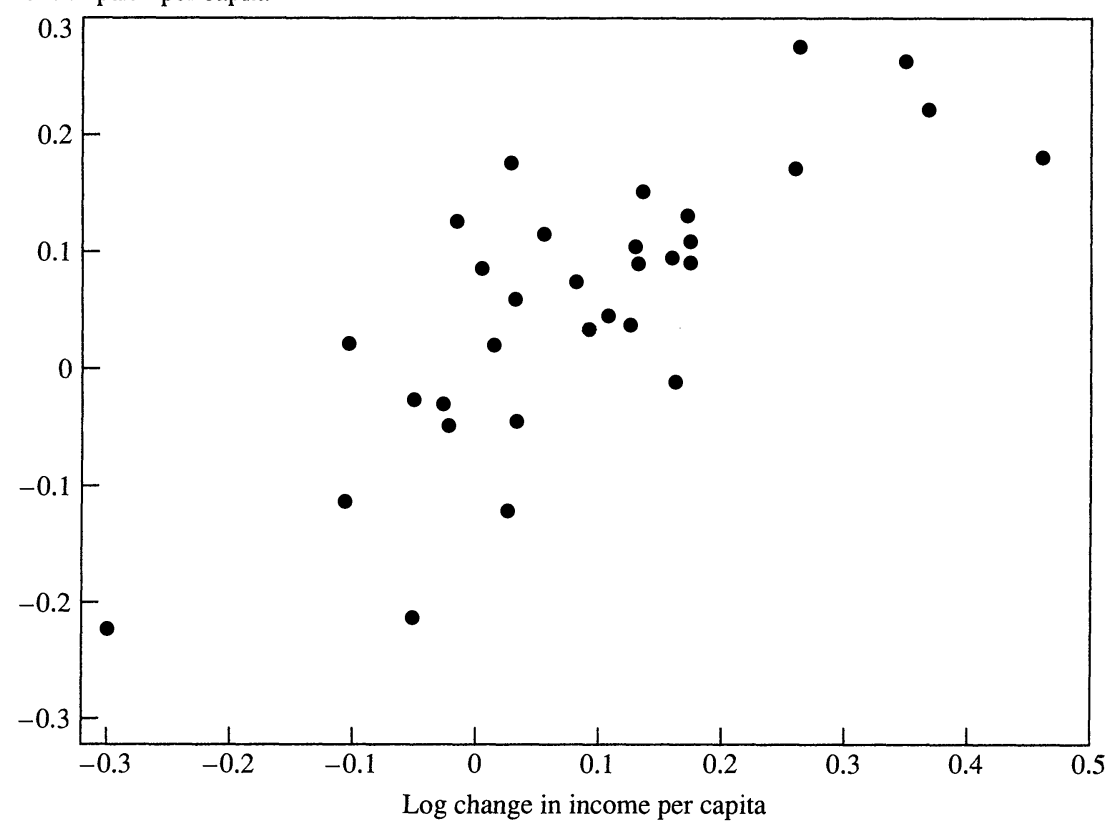

Source: Authors' calculations based on data from the CES. Data for 32 demographic groups are used (two genders, four age groups, and four education groups).

As an alternative to the micro estimates of the income-consumption correlation, we also examined the correlation between income movements and consumption movements for various demographic groups. If large changes in family income across the gender, age, and education groups of the population documented earlier reflect true changes in resources, they should predict changes in consumption as well. Figure 7 shows the change in per capita consumption and income between 1980 and 1988 for 32 demographic groups (two genders, four age groups, and four education groups). The estimated correlation between movements in income and consumption for these groups is 0.78 . We conclude that income differences across demographic groups are almost fully reflected in movements in consumption.

In summary, we conclude that income, expenditures, and consumption all tell a similar story about changes in the distribution of economic 
Table 13. Income and Consumption Poverty Rates, Selected Years, 1960-88

Percent

\begin{tabular}{lcccrrr}
\hline \multicolumn{1}{c}{ Population group } & $1960-61$ & 1963 & $1972-73$ & 1980 & 1984 & 1988 \\
\hline Poverty rates from CPS (income) & & & & & & \\
All & $\ldots$ & 20.0 & 11.6 & 11.9 & 12.6 & 12.0 \\
$\quad$ Adults & $\ldots$ & 15.2 & 8.7 & 9.2 & 10.3 & 9.6 \\
Elderly & $\ldots$ & 32.6 & 17.3 & 13.6 & 10.0 & 10.2 \\
Children & $\ldots$ & 23.5 & 15.0 & 16.9 & 19.1 & 18.3 \\
Young families & $\ldots$ & 18.9 & 11.0 & 13.3 & 15.6 & 15.6 \\
Nonelderly households & $\ldots$ & 17.6 & 10.7 & 11.6 & 13.0 & 12.2 \\
& & & & & & \\
Poverty rates from CES (consumption) & & & & & \\
All & 13.0 & $\ldots$ & 6.2 & 7.5 & 8.7 & 8.6 \\
Adults & 9.5 & $\ldots$ & 4.8 & 6.0 & 7.2 & 6.7 \\
Elderly & 13.6 & $\ldots$ & 7.0 & 6.2 & 5.4 & 3.8 \\
Children & 17.9 & $\ldots$ & 8.9 & 11.1 & 13.5 & 15.2 \\
Young families & 10.2 & $\ldots$ & 6.0 & 5.4 & 8.4 & 8.8 \\
Nonelderly households & 12.8 & $\ldots$ & 6.1 & 7.6 & 9.3 & 9.3 \\
\hline
\end{tabular}

Sources: Authors' calculations based on data from the March CPS and the CES. Poverty rates are calculated using pretax, post-transfer income, and total consumption and use the poverty thresholds after 1981. The poverty threshold is updated using the personal consumption expenditure deflator in place of the consumer price index. All poverty rates are for individuals. Adults are aged 18-64; the elderly are those above age 65; and children are below age 18 . Young families are individuals living in families with heads aged 25 to 34 . Nonelderly households are households whose head is below age 65 .

welfare in the 1980s. Standard income-based inequality measures do not seem to be a misleading guide to changes in the distribution of permanent income. All measures indicate a substantial rise in inequality in the recession of the early 1980 s and essentially no reversal of this pattern since.

Table 13 summarizes our results on income and consumption distributions, showing trends in poverty rates using the two measures. The top part of the table shows income-based measures of poverty for various demographic groups from the CPS. The bottom part of the table presents analogous poverty measures using total consumption data from the CES. ${ }^{48}$ While consumption poverty rates are below income poverty rates in every year, the time series patterns for the two measures are quite similar. Both income and consumption poverty rates declined dra-

48. Some caution is necessary in interpreting changes in poverty levels in the CES because of changes in the survey methodology between the two earlier surveys and the surveys from the 1980s. The overall increase in consumption poverty from the $1972-73$ period to the 1980 s is probably somewhat overstated because of the decline in the fraction of total consumption expenditures captured by the survey. 
matically for all groups from the early 1960 s to $1972-73$. The poverty rate of the elderly has declined relative to the nonelderly under both measures. Children and individuals in young families (those with household heads between 25 and 34 years of age) have had the most substantial increases in both income and consumption poverty over the past decade.

\section{Who Was Left Behind in the 1980s?}

Standard analyses of the welfare of the poor have stressed two benefits of macroeconomic expansion. First, the increase in labor demand in an expansion creates additional jobs for the unemployed, benefiting those with lower income. Second, the nature of jobs for existing workers changes, so that low-wage workers are able to obtain higher-paying jobs than they had in recessions. As Arthur Okun wrote in Brookings Papers nearly 20 years ago, "a high-pressure economy generates not only more jobs than does a slack economy, but also a different pattern of employment. It suggests that, in a weak labor market, a poor job is often the best job available, superior at least to the alternative of no job. A highpressure economy provides people with a chance to climb ladders to better jobs. ${ }^{49}$

Okun considered two explanations for this skill upgrading. The first was that in an expansion, wages of highly skilled workers rose more rapidly than wages of less skilled workers, leading firms to substitute the less skilled for the higher skilled. The second explanation, similar to more recent dual-labor-market models, was that some firms pay high wages to reduce turnover and improve the morale of their workers, and, in an expansion, these firms increased employment by hiring workers from the low-wage sector. Okun rejected the first explanation in favor of the second, citing the narrowing of wages in an expansion as evidence against simple demand substitution. All told, Okun calculated that the upgrading of workers across industries accounted for about 30 percent of increased wage payments in an expansion. ${ }^{50}$

49. Okun (1973, p. 234). Also see Akerlof, Rose, and Yellen (1988) for a comprehensive recent analysis of the process of cyclical upgrading.

50. Okun (1973, p. 235). 
Table 14. The Effect of the Expansions of the 1960s and 1980s on the Income Distribution

1988 dollars, unless otherwise noted

\begin{tabular}{|c|c|c|c|c|c|c|}
\hline \multirow[b]{2}{*}{ Population group } & \multicolumn{3}{|c|}{$1960 s$} & \multicolumn{3}{|c|}{$1980 s$} \\
\hline & 1963 & 1969 & $\begin{array}{c}\text { Annual } \\
\text { change } \\
\text { (percent) }\end{array}$ & 1983 & 1989 & $\begin{array}{l}\text { Annual } \\
\text { change } \\
\text { (percent) }\end{array}$ \\
\hline \multicolumn{7}{|l|}{ Sex of family head } \\
\hline Male & 11,707 & 15,421 & 4.6 & 18,520 & 20,631 & 1.8 \\
\hline Female & 5,901 & 7,553 & 4.1 & 10,380 & 11,784 & 2.1 \\
\hline \multicolumn{7}{|l|}{ Age of family head } \\
\hline Below 25 & 8,561 & 11,726 & 5.2 & 9,568 & 9,834 & 0.5 \\
\hline $25-34$ & 10,413 & 13,900 & 4.8 & 14,689 & 15,904 & 1.3 \\
\hline $35-44$ & 11,044 & 14,212 & 4.2 & 17,548 & 19,889 & 2.1 \\
\hline $45-54$ & 13,778 & 17,825 & 4.3 & 21,300 & 24,534 & 2.4 \\
\hline $55-64$ & 14,059 & 18,156 & 4.3 & 20,629 & 22,383 & 1.4 \\
\hline 65 and above & 8,131 & 9,927 & 3.3 & 13,885 & 15,294 & 1.6 \\
\hline \multicolumn{7}{|l|}{ Education of family head } \\
\hline Less than high school & 8,984 & 11,055 & 3.5 & 10,345 & 10,309 & -0.1 \\
\hline High school & 12,068 & 15,268 & 3.9 & 16,011 & 17,250 & 1.2 \\
\hline Some college & 13,925 & 17,361 & 3.7 & 18,652 & 20,802 & 1.8 \\
\hline College or more & 17,077 & 22,053 & 4.3 & 26,546 & 30,269 & 2.2 \\
\hline \multicolumn{7}{|l|}{$\begin{array}{l}\text { Head of young family, } \\
\text { aged 25-34 }\end{array}$} \\
\hline High school & 10,824 & 13,864 & 4.1 & 13,452 & 14,486 & 1.2 \\
\hline College or more & 14,476 & 19,628 & 5.1 & 22,420 & 26,550 & 2.8 \\
\hline \multicolumn{7}{|l|}{$\begin{array}{l}\text { Head of mature family, } \\
\text { aged 45-54 }\end{array}$} \\
\hline High school & 15,376 & 19,131 & 3.6 & 20,772 & 22,747 & 1.5 \\
\hline College or more & 22,120 & 25,784 & 2.6 & 31,270 & 36,731 & 2.7 \\
\hline
\end{tabular}

Source: Authors' calculations based on data from the March CPS. The table shows median adjusted family income for various characteristics of the head of the family. Adjusted family income is family income divided by the equivalence scale implicit in the federal poverty thresholds after 1981. The last column is the annual percentage change in adjusted income.

This conventional wisdom is less applicable today than it was 20 years ago. Table 14 shows changes in adjusted family income in the 1960s and 1980s for families differentiated by the demographic characteristics of the family head. Despite sustained economic expansion in the late 1980 s, benefits to the disadvantaged were not as large as in earlier postwar expansions. In the 1960s, economic gain was widely distributed. Young families (generally poorer) did better than older families, and family income increased evenly at all education levels. Among older workers, the less educated did even better than the more educated.

In the 1980s, the reverse was true. Young families, and particularly the less educated, fared much worse than older, more educated families. 
The adjusted income of families headed by individuals with fewer than 12 years of schooling, for example, fell by more than 2 percent annually relative to families headed by a college graduate. These changes in family income by demographic group parallel the sharp declines in the relative wages of young, less educated males that have been documented in the wage structure literature.

Many explanations have been proposed for changes in the U.S. wage structure in the 1980s. Most researchers have concluded that rising wage inequality largely reflects shifts in labor demand favoring more educated and more skilled workers over less educated and less skilled workers. One hypothesis is that these shifts in labor demand reflect technological changes (possibly associated with the computer revolution) that have raised the relative demand for cognitive skills and more flexible workers and reduced the relative demand for physical labor. ${ }^{51} \mathrm{~A}$ second view is that shifts in the industrial and occupational composition of employment largely associated with trade deficits and shifts in the international division of labor (outsourcing) have led to a shift in employment away from sectors that have traditionally employed less educated males. ${ }^{52}$

Certainly, the industry and occupation mix of the work force, and particularly the mix for young workers, has changed dramatically in the past decade. Tables 15 and 16 show shares of employment for all workers by industry and occupation and for men aged 25-34 with no more than a high school degree, the latter being the group most adversely affected in the 1980s. The most important difference between the two periods is the performance of manufacturing. The share of employment in manufacturing increased during the 1960s, particularly for less educated males, but fell by 25 percent in the 1980s. A similar trend is true for employment in craft and operative jobs.

Since manufacturing has traditionally paid high wages, it is clear how analysts like Okun latched onto the benefits of upgrading in expansions. Even small wage differences between manufacturing and other sectors, coupled with the huge importance of the manufacturing sector for less educated workers, could generate large fluctuations in income for the poor over the business cycle. Thus, rapid decreases in manufacturing

51. Allen (1991); Bound and Johnson (1989); Krueger (1991); Mincer (1991).

52. Murphy and Welch (1991). Alternative explanations focus on changes in wage-setting institutions, such as the decline in unions, changes in pay norms, and the erosion of the real value of the minimum wage; see Blackburn, Bloom, and Freeman (1990). 
Table 15. Industrial and Occupational Distribution, All Workers, Selected Years, 1963-89

Percent

\begin{tabular}{lrrrrr}
\hline \multicolumn{1}{c}{ Sector or job } & 1963 & 1969 & 1979 & 1983 & 1989 \\
\hline Industry & & & & & \\
Agriculture and mining & 9.0 & 6.3 & 4.5 & 4.5 & 3.7 \\
Construction & 6.1 & 6.1 & 6.6 & 6.5 & 6.8 \\
Manufacturing & & & & & \\
$\quad$ Durable & 13.9 & 14.9 & 12.8 & 11.0 & 10.3 \\
$\quad$ Nondurable & 10.9 & 10.6 & 8.7 & 8.1 & 7.2 \\
Transportation and utilities & 6.2 & 5.9 & 6.0 & 6.1 & 5.8 \\
Wholesale trade & 3.1 & 3.1 & 3.6 & 4.0 & 3.8 \\
Retail trade & 16.4 & 16.3 & 17.7 & 17.6 & 17.9 \\
Professional services & 11.9 & 13.5 & 18.3 & 20.0 & 22.7 \\
Other services & 10.5 & 9.3 & 6.9 & 7.5 & 7.4 \\
Education and welfare & 6.9 & 8.7 & 9.5 & 9.7 & 9.3 \\
Public administration & 5.1 & 5.3 & 5.2 & 5.0 & 5.2 \\
Occupation & & & & & \\
Professional and technical & 12.0 & 13.5 & 15.2 & 16.4 & 17.1 \\
Managerial & 10.2 & 9.3 & 10.3 & 12.2 & 14.0 \\
Clerical & 16.4 & 18.0 & 18.7 & 16.0 & 15.8 \\
Sales & 7.1 & 6.7 & 6.4 & 9.2 & 9.4 \\
Craftsmen & 11.7 & 12.0 & 12.6 & 11.8 & 11.3 \\
Operatives & 18.5 & 18.2 & 14.6 & 12.1 & 10.9 \\
Service & 15.1 & 14.7 & 15.3 & 15.2 & 14.5 \\
Nonfarm labor & 5.9 & 5.5 & 5.6 & 6.0 & 5.8 \\
Farm labor & 3.0 & 2.2 & 1.3 & 1.2 & 1.0 \\
\hline
\end{tabular}

Source: Authors' calculations based on data from the March CPS. Industry and occupation refer to the longestheld job in the previous year.

employment can have dramatic adverse effects on the income of the young and less skilled.

A substantial literature has attempted to assess more formally the extent to which the industrial and occupational shifts illustrated in table 15 can explain changes in the wage structure in the $1980 \mathrm{~s} .{ }^{53} \mathrm{~A}$ general conclusion is that while the observed changes can account for some of the changes in wages, these shifts do not fully explain the magnitude of the increased dispersion. Most of the wage changes have occurred within industries and occupations, however, rather than across them. ${ }^{54}$ Many have concluded from these findings that changes in relative de-

53. See Katz and Murphy (forthcoming).

54. Blackburn, Bloom, and Freeman (1990); Bound and Johnson (1989). 
Table 16. Industrial and Occupational Distribution, Males Aged 25-34 with High School Education or Less, Selected Years, 1963-89

Percent

\begin{tabular}{lrrrrr}
\hline \multicolumn{1}{c}{ Sector or job } & 1963 & 1969 & 1979 & 1983 & 1989 \\
\hline Industry & & & & & \\
$\quad$ Agriculture and mining & 6.9 & 5.7 & 6.0 & 7.5 & 6.7 \\
Construction & 12.2 & 12.6 & 15.6 & 16.3 & 18.2 \\
Manufacturing & & & & & \\
$\quad$ Durable & 22.6 & 26.5 & 22.8 & 17.9 & 16.4 \\
$\quad$ Nondurable & 14.0 & 13.3 & 10.8 & 10.4 & 9.1 \\
Transportation and utilities & 10.8 & 9.9 & 10.7 & 10.5 & 8.6 \\
Wholesale trade & 4.3 & 3.9 & 4.9 & 5.1 & 4.9 \\
Retail trade & 13.0 & 12.3 & 12.2 & 13.3 & 14.5 \\
Professional services & 5.4 & 5.2 & 6.0 & 6.9 & 8.6 \\
Other services & 4.1 & 4.6 & 5.3 & 6.8 & 8.1 \\
Education and welfare & 1.2 & 1.1 & 1.3 & 2.0 & 1.7 \\
Public administration & 5.5 & 4.9 & 4.5 & 3.5 & 3.2 \\
Occupation & & & & & \\
Professional and technical & 5.4 & 5.5 & 4.2 & 3.7 & 3.7 \\
Managerial & 7.9 & 8.7 & 7.1 & 7.4 & 8.0 \\
Clerical & 7.1 & 7.1 & 4.8 & 4.6 & 4.9 \\
Sales & 4.3 & 3.7 & 3.4 & 4.0 & 3.9 \\
Craftsmen & 24.7 & 27.0 & 32.5 & 30.9 & 29.7 \\
Operatives & 31.8 & 31.0 & 29.4 & 26.5 & 24.5 \\
Service & 6.4 & 6.5 & 7.7 & 9.7 & 11.4 \\
Nonfarm labor & 9.9 & 8.3 & 9.4 & 11.5 & 12.5 \\
Farm labor & 2.7 & 2.1 & 1.4 & 1.8 & 1.4 \\
\hline
\end{tabular}

Source: Authors' calculations based on data from the March CPS. Industry and occupation refer to the longestheld job in the previous year. High school graduates include persons who attended the first year of college but did not complete the year.

mand within sectors, driven by skill-based technological change, are a key to understanding the decline in the economic status of less educated young men.

\section{Conclusions}

The 1980s were far less beneficial to the disadvantaged than were previous periods of economic growth. Despite more than six years of sustained macroeconomic expansion, poverty rates in 1989 were above those a decade earlier, and the income share of the poor was 10 percent 
below its 1979 level. Seemingly, many of the traditional benefits of a rapidly expanding macroeconomy did not materialize during this period.

In this paper, we have shown that the failure of macroeconomic expansion to provide more benefits for the poor is not a consequence of fundamental changes in the functional distribution of income; appropriately measured, the share of income accruing to labor was relatively constant throughout the 1980s. Nor was this failure the result of compositional changes in the living arrangements of the population. Instead, we argue that the key to understanding changes in family income inequality is the rise in the returns to skill in the labor market and the associated widening in the distribution of individual labor market opportunities. The decline in manufacturing employment and other shifts in labor demand away from less educated workers in the 1980s have moderated the benefits of macroeconomic growth that might have accrued to the disadvantaged and substantially reduced progress in the war on poverty.

Given these large and continuing changes in family income distribution, it is natural to wonder if they truly reflect increased hardship among the poor. We employ data on consumption as well as income to explore this issue. We conclude that changes in consumption closely parallel changes in income during the 1980s. The share of total consumption by the lowest quintile fell by about 1 percentage point, from 8.2 to 7.3 percent, between 1980 and 1988. Similarly, in demographic groups with large declines in income, there were correspondingly large declines in consumption. Thus, the view that income movements belie a "hidden prosperity of the poor" is not evident in data on the consumption of disadvantaged individuals and groups over the past decade.

These results suggest two conclusions for policymakers. First, many of the problems of the poor (even the working poor) are not macroeconomic in nature. Although increased job availability clearly helps the disadvantaged, the conventional wisdom that industrial and occupational upgrading will lift up young, less educated workers during an expansion need not apply when shifts in relative labor demand more than offset improvements from increased aggregate job availability.

Indeed, as far as their effects on poverty or the distribution of income, changes in relative demand, if relatively prolonged, may be even more severe than they appear in the short run. William Wilson and others have argued that a form of "social hysteresis" exists among disadvantaged youths, where a decline in job availability is associated with an 
outmigration of the middle class, a deterioration in the social conditions in inner cities, and an increased incidence of behaviors harmful to future earnings prospects-criminal activity, drug use, dropping out of school, and teen childbearing. ${ }^{55}$ Richard Freeman documents a substantial increase in the fraction of young, less educated males, especially young blacks, in trouble with the law (in prison or on probation or parole) in the 1980s and presents evidence that the presence of a criminal record itself can lead to adverse labor market outcomes for youths. ${ }^{56}$

Such hysteresis effects, if present, imply that even demand shifts that are reversed in several years may have long-term effects on the living standards of the poor. In the booming Boston labor market of 1989, for example, the fraction of young blacks from poor neighborhoods who perceived more earnings potential in crime than in legitimate jobs increased substantially from the late 1970 s to the late $1980 \mathrm{~s} .{ }^{57}$ The Boston experience of the 1980s suggests that tight labor markets alone may not greatly slow the process of social disintegration in poor neighborhoods. Policies designed to directly offset adverse neighborhood and peer influences and to keep individuals in school may be far more important. Strong macroeconomic performance may be a necessary but not sufficient condition for improving the conditions of the disadvantaged.

Nonetheless, the 1980s do suggest that some transfer policies may exert a larger effect on the welfare of the disadvantaged than previously thought. Although sharp changes in relative labor demand and increased wage inequality appear widespread in industrialized countries in the 1980s, the extent to which these changes have translated into increased family poverty appears greater in the United States. ${ }^{58}$ Comparing the experience of Canada with that of the United States is particularly instructive. In recent work, Blackburn and Bloom show that earnings inequality and overall family income inequality increased substantially in Canada in the 1980s. Also, Maria Hanratty and Blank demonstrate, using a common set of poverty lines (the Canadian Low-Income "Cutoffs"), that pretransfer poverty increased more substantially in Canada than in the United States (1.9 versus 1.7 percent) between 1979 and

55. Wilson (1987).

56. Freeman (1991b).

57. Freeman (1991b).

58. See Blackburn and Bloom (1991a), Katz and Loveman (1990), and Gottschalk and Joyce (1991) for comparisons of changes in the wage structure and income inequality in various industrialized countries. 
1986. ${ }^{59}$ Differences in the generosity of the Canadian and U.S. transfer systems, however, have meant that similar increases in pretransfer poverty had very different effects on post-transfer poverty. Post-transfer poverty in Canada actually fell 0.7 percentage point from 1979 to 1986, while post-transfer poverty increased by more than 2.6 percentage points in the United States. A lesson of the 1980s may well be that renewed efforts to fashion appropriate transfer policies for the disadvantaged can be an important way to enhance outcomes for the poor, in times of both weak and strong macroeconomic performance.

\section{APPENDIX}

\section{The CES and CPS Data}

We USE DATA from the Consumer Expenditure Surveys of 1960-61, 1972-73, 1980, 1984, and 1988 to measure income and consumption changes. The 1960-61 surveys were conducted once each year and asked for annual income and consumption. The 1972-73 surveys were conducted quarterly but only annual totals are released. The 1980s surveys are conducted and released quarterly. For our 1980s samples, we use all consumer units that were present in the four-quarter period from the second quarter of the indicated year (for example, 1980:2) through the first quarter of the following year (1981:1). Our annual consumption measure adds spending for each quarter and inflates the total to an annual amount. Since the survey requests consumption information for the previous three months, this comes close to measuring calendar-year consumption. The weight for each consumer unit is the sum of the weights for each quarter in which the consumer unit was present, divided by four.

\section{Definition of Income}

In the 1960-61 and 1972-73 surveys, reported income is defined as annual income from the last interview for the consumer unit. In the

59. Blackburn and Bloom (1991b); Hanratty and Blank (forthcoming). 
1980s surveys, income information is asked for in the first and fourth quarters of the survey. We use the annualized value of income from the last completed interview as our income measure. For consumer units finishing the four interviews (about 50 percent of our sample), income thus corresponds to the earlier surveys; for consumer units censored before the last interview, income is the value reported in the first survey.

Income in the 1960-61 survey is not topcoded. Income in the 1972-73 survey is both topcoded (2.3 percent of the consumer units) and bottomcoded (6.9 percent of the consumer units). For topcoded consumer units, we use the conditional mean income above $\$ 25,000$ to impute income. ${ }^{60}$ For bottomcoded consumer units, we first identify those consumer units that reported no labor income, retirement income, or other transfer income and assign these units zero income. We then imputed average income for the remaining consumer units to match aggregate mean income below $\$ 3,000 .{ }^{61}$

In the 1980 survey, 1.7 percent of the consumer units were topcoded, with income for these consumer units set to zero. We imputed a common income for these consumer units to match average income above $\$ 30,000$. $^{62}$ In the 1984 and 1988 surveys, a relatively small share of consumer units were topcoded ( 0.5 and 0.7 percent). Only the components of income were topcoded, however, so that some income above the topcoded level is reported, although it is not exact. We leave topcoded consumer units at their topcoded value. Our results are generally insensitive to the treatment of consumer units above the topcoded values.

\section{Definition of Expenditure and Consumption}

We adjust the expenditure data to reflect two changes in definitions over time. In the 1960-61 and 1972-73 surveys, insurance payments (life and other personal insurance as well as social security and retirement contributions) were not treated as expenditures, but they were included in expenditures in the $1980 \mathrm{~s}$. We therefore add these payments to expenditures in the 1960-61 and 1972-73 surveys.

In addition, cash contributions are only surveyed in the last interview in the 1980 s, so that this item is missing for about half of the consumer

60. Bureau of Labor Statistics (1978, table 1).

61. Bureau of Labor Statistics (1978, table 1).

62. Bureau of Labor Statistics (1985, table 20). 
units. A natural solution is to impute cash contributions for the remaining consumer units and add that to total expenditures. Using predicted values for only some consumer units, however, would artificially reduce the variance of expenditures in later surveys relative to earlier ones. We thus predicted cash contributions for all consumer units in all years and used predicted cash contributions in place of actual contributions. For each year, predicted cash contributions are based on a regression of annual cash contributions on total expenditures (less cash contributions), income before taxes, the age of the household head, and dummy variables for the sex and education of the household head (details are available from the authors). Our results are generally insensitive to the treatment of cash contributions.

We form consumption from total expenditures in three steps. First, we exclude spending on owned homes for consumer units who own their house and include the imputed rental value in consumption. Since not all surveys asked about the rental value of housing (the 1960-61 and 1980 surveys did not), we imputed rental values using data on the market value of owned homes. For the 1972-73, 1984, and 1988 surveys, we first regressed the reported rental value on the market value of housing. We then used the estimated equation for 1972-73 and the reported market value in 1960-61 to predict rental values in 1960-61. We used the 1984 equation and the 1980 market value to predict rental values in 1980 . As with the cash-contribution adjustment, using imputed values in only some years would artificially lower the variance of consumption in those years relative to years with more complete information. We thus used our regressions to predict rental values for every year and used these in place of the imputed rental values.

In the second step, we subtracted spending on new and used vehicles from expenditures and added the imputed rental value of existing vehicles in its place. To find the imputed rental value, we took consumer units that reported spending on new and used vehicles and regressed the amount of that spending on total expenditures (less vehicle expenditures), expenditures squared, income before taxes, the age of the reference person, dummy variables for the sex and education of the reference person, and the size of the consumer unit. We estimated this equation for each year and predicted the value of new spending for each consumer unit. The imputed vehicle consumption is then the predicted value of new car spending times the number of vehicles the consumer unit re- 
ported owning times an assumed depreciation factor (one-eighth of purchase value). Finally, since the 1972-73 surveys capped the number of owned vehicles at two, we artificially impose this cap in other years (with little effect on the results).

Finally, we subtract life and other personal insurance expenditures, as well as employee contributions to social security and other pensions, from consumption. This will be correct if consumer units treat these as a tax or as saving rather than as consumption.

To form our component-deflated real consumption measure, we separated total consumption into twelve components: food and alcohol; apparel; shelter; fuels, utilities, and public services; household operations; house furnishings and equipment; vehicles; other transportation expenses; health care; entertainment; cash contributions; and all other goods and services. We used the category-specific CPI inflation rates to inflate consumption to 1988 dollars. Because the average CPI inflation rate is different from the PCE inflation rate over this period, the mean consumption differs between the aggregate and individually weighted estimates.

For the 1980s surveys, the definitions of the spending categories were relatively constant; some changes were made in category definitions between the pre-1980s surveys and the 1980 s surveys, however. Using the documentation provided by the BLS, ${ }^{63}$ we attempted to regroup as many of the categories into 1980 s definitions as we could. For some changes, however, we lacked sufficient detail to make the categories fully comparable.

\section{Definition of CES Sample}

Table A1 describes the CES sample and our modifications to it. The first column shows the size of the original CES sample. The first two surveys include a greater number of respondents, since they were conducted over two years. Nevertheless, we still have about 10,000 consumer units in the surveys in the 1980 s.

Because the survey methodology has changed through time, we make a number of modifications to the original sample. Our first elimination is for incomplete income reporters, as defined by the CES. The 1960-61

63. Bureau of Labor Statistics (1985, table C-6, pp. 150-51; 1978, table B, p. 21). 
Table A1. Description of CES Data

\begin{tabular}{lccccccc}
\hline & & \multicolumn{3}{c}{ Reason for elimination } & & \multicolumn{2}{c}{$\begin{array}{c}\text { Share of sample } \\
\text { (percent) }\end{array}$} \\
\cline { 3 - 4 } Year & Initial & sample & $\begin{array}{c}\text { Incomplete } \\
\text { reporter }\end{array}$ & $\begin{array}{c}\text { Missing } \\
\text { or refuse }\end{array}$ & $\begin{array}{c}\text { Final } \\
\text { sample }\end{array}$ & $\begin{array}{c}\text { Above } \\
\text { age } 65\end{array}$ & $\begin{array}{c}\text { Below } \\
\text { age 25 }\end{array}$ \\
\hline $1960-61$ & 13,728 & 0 & 9 & 13,719 & 18.9 & 4.8 \\
$1972-73$ & 19,975 & 1,072 & 215 & 18,688 & 20.0 & 8.9 \\
1980 & 9,971 & 1,609 & 252 & 8,110 & 20.9 & 9.5 \\
1984 & 10,353 & 1,080 & 689 & 8,584 & 20.2 & 9.5 \\
1988 & 9,994 & 1,447 & 348 & & 8,199 & 20.9 & 7.2 \\
\hline
\end{tabular}

Source: Authors' calculations based on data from the CES.

public-use release contains only complete reporters; the other surveys have varying amounts of incomplete responses, ranging from 5.4 percent (1972-73) to 16.1 percent (1980). The second column of table A1 shows the number eliminated by this criterion.

The second modification is from changes in the definition of complete income reporters over time. Before the 1980s, consumer units were classified as incomplete reporters if the primary family earner reported being employed but listed no employment income, or if the consumer unit reported pension or social security income but did not provide dollar amounts. In the 1980s, however, consumer units were considered complete income reporters if they listed any major source of income, independent of other income responses. Income is thus substantially understated in the 1980s for many consumer units who report being employed but having no employment income or who are in a position to collect pension or social security income but do not report any. This undercounting is offset somewhat by the treatment of consumer units with no income of any type. Before 1980, these consumer units were valid reporters if there was no evidence of refusal to answer income questions. In the 1980s, consumer units with no income of any form were considered incomplete reporters. ${ }^{64}$

To account for changing definitions of complete income responses, we imposed a uniform selection criterion across years. In addition to the CES-designated incomplete reporters, we eliminated from the pre-1980 surveys consumer units with no income from any source. For the 1980s surveys, we excluded consumer units where labor income for the head

64. See Bureau of Labor Statistics (1985) for more detail. 
of the consumer unit or spouse was not provided ("a blank resulting from a 'don't know', refusals, or other types of non-responses") and where the head of the household or spouse reported earning income (wage or salary; farm self-employment or nonfarm self-employment) but listed no labor income of any form. The number of omissions of this form is detailed in the third column of table A1. These omissions are only about 1 percent of the 1972-73 sample, but more than 6 percent of the 1984 respondents were eliminated because of incomplete information. The fourth column shows the final number of observations for each year. As best we can ascertain, our consumption distributions are unaffected by the exclusion of either set of incomplete income reporters; income distributions are only marginally affected by our additional exclusions beyond complete income reporters.

A final modification is for households of different ages. Since much of our work focuses on changes in market opportunities, we present results for both the total sample and for consumer units headed by nonelderly individuals. As table A1 shows, about 20 percent of the consumer units are headed by an elderly individual. A second issue concerns the treatment of college students. The CES has not been uniform on this over time. In the 1960-61 and 1972-73 surveys, college students living away from home were considered part of their parents' consumer unit; in the 1980s surveys, these students were treated as separate consumer units. Since income is low and consumption is high for many college students, this change could bias measures of consumption inequality. We have thus explored the results omitting consumer units headed by a person below the age of 25 (shown in the last column of the table). None of our results change substantially with this exclusion, so we do not present them. These results are available on request.

\section{Description of CPS Data}

Our income distributions are primarily based on the March Consumer Population Survey Annual Demographic Supplements. We use as our base sample all persons in the United States; we thus do not automatically exclude persons in the military or living in group quarters.

To form poverty rates, we classify families in all years into the 48 official categories used after $1981^{65}$ and use these thresholds. To form a

65. Bureau of the Census (1988, table A-2). 
poverty line deflated by the personal consumption expenditures index rather than the consumer price index, we assume that the 1967 poverty line was the appropriate measure of poverty and adjust the poverty line from that year.

Our definition of families differs from the census definition in two respects. First, we include individuals (persons living alone or living in a household but not related to the household head) as families, while the census definition excludes these persons. Second, and more minor, we count unrelated subfamilies as families for all years, although the census excludes them from families after 1979. Since most of our tabulations are performed for persons rather than for families, these issues are not relevant; they are relevant in our distribution of the family breakdown of the population.

Annual income data is topcoded in all years, but the topcoding affects a relatively small share of the population after 1979 . For the years before 1979, we assume that the income of topcoded families was 1.4 times their reported income. We have found our results insensitive to the treatment of topcoded individuals.

\section{Comparison of CES and CPS Data}

Table A2 compares per capita income in the CES with per capita income in the CPS. ${ }^{66}$ The two income measures are conceptually similar: both include wage and salary income, social security and pension income, and government cash transfers. Neither includes employer contributions to health insurance or other noncash income. The first three columns present per capita income for the CES (our modified completeresponse definition) and the CPS. The table shows a dramatic decline in income in the CES relative to the CPS. Income in 1972-73 is 5 percent higher in the CES than in the CPS, but income in the 1980s is 8-12 percent lower in the CES. The next three columns show similar comparisons for the nonelderly sample. The change is similar but slightly less dramatic. Income in the CES is still 11 percent below income in the CPS

66. There is no exact comparison between CES consumer units and CPS households. A household in the CPS is a group of persons sharing living quarters, independent of whether there are any shared expenses. Persons in the same consumer unit are either related or share at least two of the three major expense categories: housing, food, and other living expenses. We use per capita income to eliminate some of these problems. 
Table A2. Comparison of CES and CPS per Capita Income 1988 dollars, unless otherwise noted

\begin{tabular}{lccccccc}
\hline & \multicolumn{3}{c}{ All households } & & \multicolumn{3}{c}{ Nonelderly households } \\
\cline { 2 - 5 } \cline { 7 - 8 } Year & CES & CPS & $\begin{array}{c}\text { CES/CPS } \\
\text { (ratio) }\end{array}$ & CES & CPS & $\begin{array}{c}\text { CES/CPS } \\
\text { (ratio) }\end{array}$ \\
\hline $1960-61$ & 7,155 & $\ldots$ & $\ldots$ & 7,136 & $\ldots$ & $\ldots$ \\
$1972-73$ & 10,746 & 10,191 & 1.054 & 10,844 & 10,277 & 1.055 \\
1980 & 10,169 & 10,987 & 0.926 & 10,302 & 11,067 & 0.931 \\
1984 & 10,986 & 11,913 & 0.922 & 11,217 & 11,877 & 0.944 \\
1988 & 11,379 & 12,908 & 0.882 & & 11,591 & 12,984 & 0.893 \\
\hline
\end{tabular}

Source: Authors' calculations based on data from the March CPS and the CES. The CES sample excludes incomplete reporters and persons with missing or refused income. CPS income is household income per capita. Data are adjusted to 1988 using the personal consumption expenditure deflator for each year.

in 1989, with the largest change occurring between 1972-73 and 1980. A comparison of the two columns indicates that income underreporting is greater for the elderly than for the nonelderly. The decline in income in the CES relative to the CPS has been noted by other researchers, ${ }^{67}$ but there has been little satisfactory explanation. For our income tabulations, we use the more complete CPS income, although as table 8 shows, the income shares at a point in time look relatively similar.

\section{Quality of CES Consumption Data}

The expenditure data in the CES appear to be more consistent across surveys, although it too has trended down relative to other measures. Raymond Gieseman shows that CES spending on food declined from 85 percent of the PCE total in 1980 to 75 percent in $1984 .{ }^{68}$ Most of the other components, however, remained relatively similar. In separate studies, Slesnick and John Sabelhaus compare CES consumption data with data in the national income accounts for the 1970s and 1980s.${ }^{69}$ For almost all categories of consumption, there is a decline in consumption in the CES relative to personal consumption expenditures in the national income accounts. Although some of this is due to items not covered by the CES (such as medical payments by insurance companies and banking services), the decline occurs in areas of substantial overlap as well (such as food and energy expenditures).

67. Bureau of Labor Statistics (1985, pp. 4-5).

68. Gieseman (1987).

69. Slesnick (1991b); Sabelhaus (1990). 


\section{Comments and Discussion}

David Card: In analyzing the effects of macroeconomic variables on the aggregate poverty rate, I think it is helpful both conceptually and empirically to separate the effects of these variables on the mean and dispersion of family income. To see why, suppose that family income is approximately $\log$ normally distributed with mean $m$ and standard deviation $s$, and let $c$ denote the poverty line. In this stylized setting the poverty rate is $N[(c-m) s]$, where $N[$.$] is the normal distribution function.$ Increases in median family income imply an increase in the mean of log income and a reduction in the poverty rate. On the other hand, as long as the poverty line is below median income, increases in the dispersion of income imply an increase in the poverty rate (holding constant median income).

It is my impression that in earlier periods of economic growth median family income grew relatively quickly and the dispersion in income fell (at least relative to trend). Both effects worked in the same direction, implying a strong negative correlation between growth and poverty rates. During the economic recovery of the 1980 s, however, there was an increase in the inequality of income, tending to offset the povertyreducing effects of higher median family income. In future work on poverty and growth it would be useful to know (1) whether the historical link between median family income and simple macroeconomic indicators was maintained in the $1980 \mathrm{~s}$, (2) whether income dispersion was pro- or countercyclical in the period up to 1983, and (3) how much of the "excess poverty" depicted in David Cutler and Lawrence Katz's figure 2 can be attributed to the rise in the dispersion of family income over the $1980 \mathrm{~s}$ and how much to the relatively sluggish growth of median income. 
Table 1. Poverty Rates of Individuals in 1979 and 1989, by Census Region Percent

\begin{tabular}{|c|c|c|c|}
\hline \multirow[b]{2}{*}{ Region } & \multicolumn{2}{|c|}{ Poverty rate } & \multirow{2}{*}{$\begin{array}{l}\text { Change } \\
\text { in rate }\end{array}$} \\
\hline & 1979 & 1989 & \\
\hline New England & 9.6 & 7.2 & -2.4 \\
\hline Middle Atlantic & 11.7 & 11.0 & -0.7 \\
\hline East North Central & 10.3 & 11.9 & 1.6 \\
\hline West North Central & 11.0 & 11.7 & 0.7 \\
\hline South Atlantic & 13.9 & 12.7 & -1.2 \\
\hline East South Central & 18.7 & 18.6 & -0.1 \\
\hline West South Central & 15.6 & 17.8 & 2.2 \\
\hline Mountain & 11.9 & 13.1 & 1.2 \\
\hline Pacific & 11.1 & 12.3 & 1.2 \\
\hline All United States & 12.4 & 12.8 & 0.4 \\
\hline
\end{tabular}

Sources: The 1979 data are based on the 1980 census and are formed from weighted averages of state poverty rates reported in Detailed Population Characteristics, Series PC80-1-D, table 245. The 1989 data are based on Bureau of the Census (1991a, table 20).

\section{Are Growth and Poverty Still Related?}

Cutler and Katz conclude that in many respects the main problems of the poor (even the working poor) are not macroeconomic in nature. I cannot disagree. Three decades of study of microdata on earnings, unemployment, and poverty confirm that most of the difficulties faced by the poor are associated with individual-specific factors, such as education, health, and family background. Nevertheless, I hesitate to conclude that economic prosperity at the aggregate level is unimportant. My reasoning is based on "macroeconomic" evidence at a slightly lower level of aggregation. For example, my table 1 presents data on poverty rates in 1979 and 1989 in the nine census regions of the United States. Despite the relative stability of the national poverty rate, different regions experienced very different poverty trends, ranging from a 2.4 percentage point decline in New England to a 2.2 percentage point increase in the West South Central region (Arkansas, Texas, and Oklahoma). These changes are highly correlated with regional changes in unemployment.

The data in table 1 may be very relevant for thinking about the connection between macroeconomic growth, changes in median income, changes in the dispersion of income, and changes in poverty. The recov- 
ery of the 1980s was associated with an unusual dispersion in growth rates across different regions and sectors of the economy. This contributed to the overall dispersion in individual and family income across the country and to the breakdown in the historical link between aggregate growth and poverty. Nevertheless, within individual labor markets there was still a strong connection between "macroeconomic" performance and poverty. ${ }^{1}$ I conjecture that the same process of skill upgrading measured by Arthur Okun using national data for the 1960s and 1970s occurred in the booming regions of the country in the 1980s. However, these changes occurred at the same time that other factors led to an increase in the dispersion of incomes across regions.

\section{Measuring Consumption versus Income}

Much of the work in the authors' paper is devoted to analyzing the changing distribution of consumption. Although I commend this effort, I believe that some of the criticisms of income statistics as a measure of individual well-being are misplaced. One criticism is that these statistics contain transitory fluctuations that over- and understate true economic well-being. This is surely true, but of little significance in interpreting mean income levels by demographic characteristic (schooling or race, for example). Mean earnings levels of less educated workers have fallen sharply over the 1980s. These losses have not been offset by increased transfers (as was apparently the case in Canada). It follows directly that these individuals, who form the bulk of the poor, are permanently worse off. $^{2}$

Even at the individual level only some part of the observed year-toyear fluctuations in earnings is transitory. Most studies suggest that 60 70 percent of the innovations in individual income persist indefinitely. Unless this ratio has changed over time, there is no reason to suspect that changes in the distribution of observed annual income give a misleading picture of changes in the distribution of "permanent" income.

1. A similar conclusion is reached by Freeman (1991a) in an analysis of the labor force status of black youth across different cities in the United States.

2. This is essentially the idea behind Cutler and Katz's figure 7. 
Robert E. Hall: Rising economic inequality was a striking feature of the U.S. social landscape in the 1980 s. Successful people enjoyed substantial gains in real income during the decade, while real income fell among the less educated and disadvantaged parts of the population. Research seems to agree that this finding is not a statistical artifact. Both this paper by David Cutler and Lawrence Katz as well as the complementary paper in this volume by Chinhui Juhn, Kevin Murphy, and Robert Topel find large increases in inequality in the 1980s.

Cutler and Katz start from the observation that the 1980s saw a long and powerful expansion in overall economic activity. The most salient historical comparison is to the expansion of the 1960s. In the earlier expansion, the income distribution tightened. As Arthur Okun observed, the high-pressure economy conferred differential benefits on workers with lower levels of earnings. Cutler and Katz add to the evidence that the expansion of the 1980s was accompanied by the opposite change, a widening of the income distribution. They carry out a detailed and immensely impressive investigation of the sources of that widening. To get a sense of the magnitude of their overall accomplishment, just consider the amount of work that went into the project described in footnote 43 .

Cutler and Katz consider five sources of the changes in the income distribution. I list them in declining order of empirical significance: (1) increasing dispersion of earnings within industries, which they find to be by far the most important factor; (2) a decline, rather than an expansion, in manufacturing, a sector that offers high earnings to less educated workers and a source of declining inequality in the 1960s; (3) cutbacks in transfer programs; (4) rising capital income, which goes virtually entirely to the top of the income distribution; and (5) declining numbers of earners in low-income families.

With respect to increasing dispersion of earnings within industries, Cutler and Katz leave to Juhn, Murphy, and Topel the interesting task of breaking down the change into increases in the dispersion of annual hours of work. The latter authors show that the two factors are about equally important in the overall increase in earnings dispersion. They show that there was a large increase in the nonemployment rate at the bottom of the wage distribution (but not elsewhere in the distribution). They also show that there was a large decline in real wages at the bottom of the distribution. 
Cutler and Katz's concern with measuring sources rather than providing fundamental explanations leaves the reader with only a glimpse of their thinking about those explanations. They remark that the earnings decline at the bottom of the distribution arises from "changes in labor demand against the less skilled." It is the duty of the discussant of this type of paper to speculate freely on the mechanisms underlying the empirical findings. The skill-bias hypothesis may find some support, even though it contradicts a traditional belief about technical progress. That belief holds that technical change is a slow, steady process. What was different about technical change in the 1960s that made it favor the disadvantaged, when in the 1980s it went against them? Specific innovations, especially those based on modern electronics, are not obviously biased against the poorly educated. For example, McDonald's now uses cash registers with pictures of each item, rather than having its cashiers enter prices. On the other hand, recent work by Alan Krueger shows that workers who use computers enjoy a wage premium of 10 to 15 percent and that the rapid growth in the fraction of the labor force using computers is an important factor in changing the distribution of earnings. ${ }^{1}$

Although it is true that changes in the composition of output have favored the educated desk worker over the less educated worker on the plant floor, this paper and others are persuasive that the changing composition of output is a small part of the story. And this paper makes it clear why the composition effects must be small. Even the professional services-FIRE sector, the quintessential growth industry of the 1980s, employs a substantial number of workers who have no college (see table 16).

Pursuing my duty to speculate freely, I note that Cutler and Katz give no attention to one of the social forces that has received a good deal of attention in other commentary on the 1970s and 1980s, the deferral of adulthood. Table 14 shows that the biggest contrast between the $1980 \mathrm{~s}$ and the 1960s was in families with the youngest heads of households (less than 25 years of age). The trend during the 1980s was toward starting serious adult activities later-there was a pronounced increase in the median age of marriage and in childbearing, and probably at least as large a deferral in the onset of a serious career. Some part of the growing lower tail of the earnings distribution may be the result of people in their

1. Krueger (1991). 
twenties continuing teenage labor supply patterns. On the other hand, a widening of the wage distribution has occurred among earlier cohorts as well, so a good part of the explanation must rest on other factors.

This is a good place to make a point that has equal importance for the paper by Juhn, Murphy, and Topel. It is tempting to say that whatever happened in the labor market for low-wage workers was an adverse demand shift, because both employment and the wage declined. That conclusion rests on the untenable hypothesis that the workers were offering the same service at the beginning and end of the period. If a particular group has lowered the quality of its labor services, one would expect to see exactly the combination of lower wage and lower employment without any shift in demand for the group. Hence the supply side of the labor market cannot be neglected.

In the same vein, I was surprised at the amount of attention that the "hidden prosperity" view of Christopher Jencks received here, in comparison with the little mention of the social indicators that show pathological change.

To probe the outer limits of speculation permissible, I think the hypothesis needs to be considered that disadvantaged workers have far fewer problem-solving skills when they leave school today, as compared with earlier decades. More television and less parental attention at home, combined with the collapse of educational effectiveness in innercity school systems, leaves the labor-force entrant less well equipped to deal with the challenges of any type of higher-wage job, blue or white collar. Again, the observation that wages have declined does not foreclose this line of explanation at all. But the effects that are uniform across cohorts cannot be explained by the adverse characteristics of the younger cohorts.

Cutler and Katz have cut off an obvious area for my speculation, the difference between income and consumption. Irving Fisher convinced me a long time ago that the right measure of well-being is consumption, not income. Cutler and Katz make a substantial contribution to the literature on growing inequality by showing that much the same growth in inequality has occurred in consumption. Growth in the dispersion of transitory income is not the reason for growing income inequality.

Still, the evidence of consumption does not completely close the issue of the dynamics of poverty. Liquidity constraints are a fact of life for low-income families. We should not infer that a family's expected future 
income is low just because its consumption today is low. The rise in the incidence of poverty would be less worrisome if today's poor family typically moved well up the income distribution in the future. In this respect, it would be desirable to look at the distribution of consumption over much longer periods than a year. I doubt that such an investigation would much change the dismal conclusions, however.

Cutler and Katz's investigation of the distribution of consumption has uncovered the disturbing fact that the Consumer Expenditure Survey, potentially the best data source, has drifted badly relative to the CPS (with respect to income) and the national income accounts (with respect to consumption). I am not sure I share their confidence in the reliability of changes in the distribution of consumption given the large problems revealed in table A2.

Although the authors consider the differences between total compensation and cash wages, there are a couple of elements omitted from the actual distributional measurements that are big enough to make a difference. First, over the period considered, there was a large increase in payroll taxes. The best way to include their effect in the distributional calculation (short of measuring lifetime consumption) would be to include the accrual of pension and other deferred benefits earned by the worker as a result of one year's work. Given the progressivity of social security benefits, there could be a significant tightening of the distribution of earnings. Second, there was continuing growth in employer-financed fringes over the period. These probably have their biggest proportional effect toward the middle of the earning distribution, so the effect of imputing their value to the individual would be smaller for the lower-tail calculations that most concern Cutler and Katz.

This paper and the companion one by Juhn, Murphy, and Topel cover the descriptive ground very thoroughly. I have very few suggestions for practical improvements. I congratulate the authors for an incredible piece of work and a highly informative product. The next step, it seems to me, is to pursue the fundamental explanations, whether on the side of technology (that is, demand) or that of worker characteristics and other supply issues. 


\section{General Discussion}

Robert Topel was skeptical of Robert Hall's explanation that a change in the quality of the workers entering the labor market was responsible for the deterioration of incomes in the lower part of the distribution. He noted that inequality has been rising within all cohorts, a fact that did not accord with Hall's explanation. Lawrence Katz added that the proliferation of computers in the workplace was the kind of development consistent with the technological explanation for the changing income distribution. Computers shift the mix of labor toward higher-educated workers, and people who work with computers generally receive larger wage premiums than people who do not. However, Hall noted that computers were often used to adapt jobs to the skills of the available work force, citing the example of automatic cash registers whose keys used pictures of the items being sold.

Edward Gramlich asked whether the growing importance of fringe benefits in compensation, particularly the large and exploding cost of health insurance, could explain some of the observed wage shift. But Katz replied that taking account of fringe benefits like health insurance and pension benefits exacerbates the overall picture of rising inequality. George Perry suggested that the decline in the U.S. minimum wage relative to average wages could help explain the worsening relative position of low-income families. Katz did not agree, because the minimum wage was mainly relevant for people in the 16- to 20 -year-old age group. William Nordhaus suggested that the favorable experience of the top 5 percent of the income distribution was an even bigger puzzle than the experience of individuals in lower income categories. He knew of no ready sociological or technological explanation for why the skills or market value of high-income individuals suddenly increased during the $1980 \mathrm{~s}$.

Robert Gordon observed that countries in Europe have not experienced the same increase in inequality as the United States has and suggested looking for differences that could explain the dissimilar experience of the disadvantaged. He suggested that more flexible U.S. labor markets, at a time of low productivity growth, might have led not only to low real wage growth but indirectly to an increase in inequality. One clue was that the ratio of productivity growth in nonmanufacturing to 
manufacturing was 0.9 in France and only 0.1 in the United States. Perhaps the U.S. economy, with its flexible labor markets, was able to create many service-sector jobs with low productivity and low wages. Gordon also suggested that the different experiences of Europe and the United States cast doubt on the idea that a technological shift reduced the demand for low-skilled workers, since technology crosses borders rapidly. Katz replied that not all European countries have had experiences so different from the United States, noting that the United Kingdom looks very much like the United States on every measure of withingroup inequality and also that Canada experienced a big increase in overall inequality across households. Katz suggested that one reason France is different is because of its minimum wage policy. He believed a major shift in relative demand in favor of more skilled workers has occurred in most countries. However, different countries respond to the shift in different ways because of their labor market institutions. In places like France, with more rigidities in the labor market, the shift shows up more in higher unemployment of the less skilled and less in widening income disparities. 


\section{References}

Akerlof, George A., Andrew K. Rose, and Janet L. Yellen. 1988. "Job Switching and Job Satisfaction in the U.S. Labor Market." BPEA, 2:1988, 495-582.

Allen, Steven G. 1991. "Technology and the Wage Structure." Unpublished paper, North Carolina State University (May).

Bane, Mary Jo. 1986. "Household Composition and Poverty." In Fighting Poverty: What Works and What Doesn't, edited by Sheldon H. Danziger and Daniel H. Weinberg. Cambridge, Mass.: Harvard University Press.

Bartik, Timothy J. 1991. Who Benefits from State and Local Economic Development Policies? Kalamazoo, Mich.: W.E. Upjohn Institute for Employment Research.

Blackburn, McKinley L., and David E. Bloom. 1991a. "Changes in the Structure of Family Income Inequality in the U.S. and Other Industrialized Nations during the 1980s." Unpublished paper, University of South Carolina and Columbia University (June).

1991b. "The Distribution of Family Income: Measuring and Explaining Changes in the 1980s for Canada and the United States." Working Paper 3659. Cambridge, Mass.: National Bureau of Economic Research (March).

Blackburn, McKinley L., David E. Bloom, and Richard B. Freeman. 1990. "The Declining Economic Position of Less Skilled American Men." In A Future of Lousy Jobs? The Changing Structure of U.S. Wages, edited by Gary Burtless. Washington: Brookings.

Blank, Rebecca M. 1991. "Why Were Poverty Rates So High in the 1980s?" Unpublished paper, Northwestern University (July).

Blank, Rebecca M., and Alan S. Blinder. 1986. "Macroeconomics, Income Distribution, and Poverty." In Fighting Poverty: What Works and What Doesn't, edited by Sheldon H. Danziger and Daniel H. Weinberg. Cambridge, Mass.: Harvard University Press.

Blinder, Alan S., and Howard Y. Esaki. 1978. "Macroeconomic Activity and Income Distribution in the Postwar United States." Review of Economics and Statistics 60: 604-09.

Bosworth, Barry, Gary Burtless, and John Sabelhaus. 1991. "The Decline in Saving: Evidence from Household Surveys." BPEA, 1:1991, 183-241.

Bound, John, and George Johnson. 1989. "Changes in the Structure of Wages During the 1980's: An Evaluation of Alternative Explanations." Working Paper 2983. Cambridge, Mass.: National Bureau of Economic Research (May).

Bureau of the Census. 1988. Poverty in the United States: 1986. Current Population Reports, Series P-60, No. 160. Washington: U.S. Department of Commerce.

- 1989. Money Income of Households, Families, and Persons in the United States: 1988. Current Population Reports, Series P-60, No. 166. Washington: U.S. Department of Commerce. 
1990. Trends in Income by Selected Characteristics: 1947-1988. Current Population Reports, Series P-60, No. 167. Washington: U.S. Department of Commerce.

1991a. Poverty in the United States: 1988 and 1989. Current Population Reports, Series P-60, No. 171. Washington: U.S. Department of Commerce. - 1991b. Money Income of Households, Families, and Persons in the United States: 1988 and 1989. Current Population Reports, Series P-60, No. 172. Washington: U.S. Department of Commerce.

Bureau of Labor Statistics. 1978. Consumer Expenditure Survey: Integrated Diary and Interview Survey, 1972-73. Bulletin No. 1992. Washington: U.S. Department of Labor.

- 1985. Consumer Expenditure Survey: Interview Survey, 1980-81. Bulletin No. 2225. Washington: U.S. Department of Labor.

Committee on Ways and Means. 1990. 1990 Green Book, Background Material and Data on Programs within the Jurisdiction of the Committee on Ways and Means. Washington: U.S. House of Representatives.

Ellwood, David T. 1988. Poor Support: Poverty in the American Family. New York: Basic Books.

Ellwood, David T., and Jonathan Crane. 1990. "Family Change among Black Americans: What Do We Know?" Journal of Economic Perspectives 4 (Fall): 65-84.

Ellwood, David T., and Lawrence H. Summers. 1986. "Poverty in America: Is Welfare the Answer or the Problem?" In Fighting Poverty: What Works and What Doesn't, edited by Sheldon H. Danziger and Daniel H. Weinberg. Cambridge, Mass.: Harvard University Press.

Freeman, Richard B. 1991a. "Employment and Earnings of Disadvantaged Young Men in a Labor Shortage Economy." In The Urban Underclass, edited by Christopher Jencks and Paul E. Peterson. Washington: Brookings.

_. 1991b. "Crime and the Economic Status of Disadvantaged Young Men." Unpublished paper, Harvard University (March).

Friedman, Milton. 1957. A Theory of the Consumption Function. Princeton: Princeton University Press and National Bureau of Economic Research.

Gieseman, Raymond. 1987. "The Consumer Expenditure Survey: Quality Control by Comparative Analysis." Monthly Labor Review 110 (March): 8-14.

Gottschalk, Peter, and Mary Joyce. 1991. "Changes in Earnings Inequality-An International Perspective." Unpublished paper, Boston College (June).

Gramlich, Edward M., Richard Kasten, and Frank Sammartino. 1990. "Growing Inequality in the 1980s: The Role of Taxes and Transfers." Unpublished paper, University of Michigan (June).

Hall, Robert E. 1990. The Rational Consumer: Theory and Evidence. Cambridge, Mass.: MIT Press.

Hanratty, Maria, and Rebecca M. Blank. Forthcoming. "Down and Out in North America: Recent Trends in Poverty Rates in the United States and Canada." Quarterly Journal of Economics (forthcoming). 
Jacobs, Eva, and Stephanie Shipp. 1990. "How Family Spending Has Changed in the U.S." Monthly Labor Review 113 (March): 20-27.

Jencks, Christopher. 1984. "The Hidden Prosperity of the 1970s." Public Interest 77 (Fall): 37-61.

Jencks, Christopher, and Barbara Boyle Torrey. 1988. "Beyond Income and Poverty: Trends in Social Welfare among Children and the Elderly since 1960." In The Vulnerable, edited by John L. Palmer, Timothy Smeeding, and Barbara Boyle Torrey. Washington: Urban Institute Press.

Jorgenson, Dale. 1990. "Aggregate Consumer Behavior and the Measurement of Social Welfare." Econometrica 58: 1007-40.

Juhn, Chinhui, Kevin M. Murphy, and Brooks Pierce. 1991. "Wage Inequality and the Rise in Returns to Skill."Journal of PoliticalEconomy (forthcoming).

Karoly, Lynn A. 1990. "The Trend in Inequality among Families, Individuals, and Workers in the United States: A Twenty-Five Year Perspective." Unpublished paper, The RAND Corporation (May).

Katz, Lawrence F., and Gary Loveman. 1990. "An International Comparison of Changes in the Structure of Wages: France, the United Kingdom, and the United States." Unpublished paper, Harvard University (December).

Katz, Lawrence F., and Kevin M. Murphy. Forthcoming. "Changes in Relative Wages, 1963-1987: Supply and Demand Factors." Quarterly Journal of Economics (forthcoming).

Krueger, Alan B. 1991. "How Computers Have Changed the Wage Structure: Evidence from Microdata, 1984-89." Unpublished paper, Princeton University (August).

Lazear, Edward P., and Robert T. Michael. 1988. Allocation of Income within the Household. Chicago: University of Chicago Press.

Levy, Frank, and Richard J. Murnane. 1991. "U.S. Earnings Levels and Earnings Inequality: A Review of Recent Trends and Proposed Explanations." Journal of Economic Literature (forthcoming).

Lillard, Lee, and James P. Smith. 1986. "What Do We Really Know about Wages? The Importance of Nonreporting and Census Imputation." Journal of Political Economy 94: 489-506.

Mayer, Susan E., and Christopher Jencks. 1989. "Poverty and the Distribution of Material Hardship.” Journal of Human Resources (Winter): 88-113.

—. 1991. "Recent Trends in Economic Inequality in the United States: Income vs. Expenditures vs. Material Well-Being." Unpublished paper, University of Chicago and Northwestern University (October).

McNeil, John. 1988. "Estimates of Poverty Including the Value of Noncash Benefits." Technical Paper 58. Washington: Bureau of the Census (August).

Mincer, Jacob. 1991. "Human Capital, Technology, and the Wage Structure: What Do Time Series Show?” Working Paper 3581. Cambridge, Mass.: National Bureau of Economic Research (January).

Mishel, Lawrence, and David M. Frankel. 1991. The State of Working America. Armonk, N.Y.: M. E. Sharpe. 
Murphy, Kevin M., and Finis Welch. 1991. "The Role of International Trade in Wage Differentials." In Workers and Their Wages: Changing Patterns in the United States, edited by Marvin H. Kosters. Washington: The AEI Press.

- Forthcoming. "The Structure of Wages." Quarterly Journal of Economics (forthcoming).

Okun, Arthur M. 1973. "Upward Mobility in a High-pressure Economy." BPEA, 1:1973, 207-52.

Poterba, James M. 1991. “Is The Gasoline Tax Regressive?” In Tax Policy and the Economy 5, edited by David Bradford. Cambridge, Mass.: MIT Press and National Bureau of Economic Research.

Ruggles, Patricia. 1990. Drawing the Line: Alternative Poverty Measures and Their Implications for Public Policy. Washington: Urban Institute Press.

Sabelhaus, John. 1990. "Measuring the Secular Decline in U.S. Saving with Survey Data." Unpublished paper, Brookings and Towson State University, Towson, Md. (October).

Slesnick, Daniel T. 1991a. "The Standard of Living in the United States." Unpublished paper, University of Texas, Austin (June).

— 1991b. "Aggregate Consumption and Saving in the Postwar United States." Unpublished paper, University of Texas, Austin (June).

- 1991c. "Gaining Ground: Poverty in the Postwar United States." Unpublished paper, University of Texas, Austin (July). . 1991d. "Consumption, Needs and Inequality." Unpublished paper, University of Texas, Austin (September).

Van der Gaag, Jacques, and Eugene Smolensky. 1982. "True Household Equivalence Scales and Characteristics of the Poor in the United States." Review of Income and Wealth 28: 17-28.

Wilson, William J. 1987. The Truly Disadvantaged: The Inner City, the Underclass, and Public Policy. Chicago: University of Chicago Press. 